2020-09-03

\title{
Mindful Self-Care and Resilience in First-Year Undergraduate Students
}

McGuinness, Claire

McGuinness, C. (2020). Mindful Self-Care and Resilience in First-Year Undergraduate Students (Unpublished master's thesis). University of Calgary, Calgary, AB.

http://hdl.handle.net/1880/112500

Downloaded from PRISM Repository, University of Calgary 


\title{
UNIVERSITY OF CALGARY
}

Mindful Self-Care and Resilience in First-Year Undergraduate Students

by

Claire McGuinness

\begin{abstract}
A THESIS
SUBMITTED TO THE FACULTY OF GRADUATE STUDIES

IN PARTIAL FULFILMENT OF THE REQUIREMENTS FOR THE DEGREE OF MASTER OF SCIENCE
\end{abstract}

GRADUATE PROGRAM IN EDUCATIONAL PSYCHOLOGY

CALGARY, ALBERTA

SEPTEMBER, 2020

(C) Claire McGuinness 2020 


\begin{abstract}
The current study investigates mindful self-care and resilience as predictors of flourishing in first-year undergraduate students. Mindful self-care includes a) mindful awareness and assessment of one's internal needs and external demands and b) intentional engagement in specific practices of self-care to address needs and demands in a manner that serves one's wellbeing and personal effectiveness. Mindful self-care has been shown to reduce stress in postsecondary students enrolled in a medical degree. However, there is a lack of research into the role that self-care plays in first-year undergraduate students. Resilience - the process of adequately responding to and adapting in the face of adversity - can also be a protective factor in the transition to post-secondary education. The three-factor model of personal resilience includes three core developmental systems (sense of mastery, sense of relatedness, and emotional reactivity). A sample of 177 first-year undergraduate students (26.9\% males) completed online measures including Mindfulness Self-Care Scale and Resilience Scale for Young Adults. The present study supports the premise that aspects of mindful self-care and resilience predicts flourishing in first-year undergraduate students. In addition, resilience predicts flourishing above and beyond mindful self-care. Implications for practice and future research directions are discussed.
\end{abstract}

Keywords: Mindful Self-Care, Resilience, Flourishing 


\section{Acknowledgements}

This has been quite a journey and I would not have reached my destination without the support, love, and encouragement of many people. First and foremost, I would like to acknowledge my supervisor and committee members, Dr. David Nordstokke, Dr. Yvonne Hindes, and Dr. Sharon Robertson for their commitment, feedback, and guidance towards my successful completion of my thesis.

To my parents and family, especially my dads Steve and Gary, thank you for believing in me and for your ongoing encouragement; you have helped me become more resilient. To my mom, thank you for your input regarding my thesis edits.

Many heartfelt thanks go to my friends Catherine, Tina, and Ocean for serving as a wonderful distraction on days when this all seemed too much. A special thank you to my friends Bethany and Rachel for their invaluable statistical and editorial assistance and for their patience when I called or texted just to bounce one more idea around. You all have gotten me through the most difficult and stressful times of my degree.

I would also like to thank my friend and mentor Dr. Calandra Speirs for her unwavering support and providing me with pictures of her cats when I needed a distraction. Thank you for believing in me even before I started my Masters.

A huge thank you to my partner, Andres Cardona, for his support in editing my writing and patience while I completed my thesis. The sugar cookies you made got me through those long endless nights of writing.

Lastly, thank you to all the individuals who took time to participate in this study. This project would not be possible without your time and dedication. 


\section{Table of Contents}

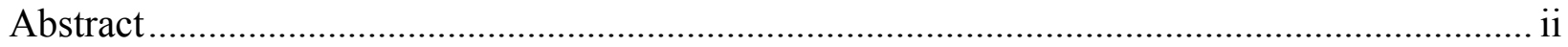

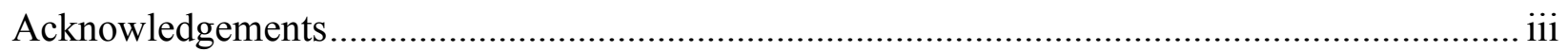

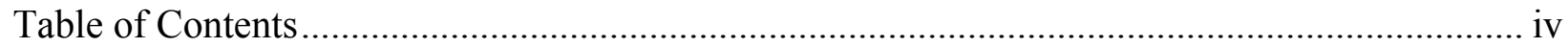

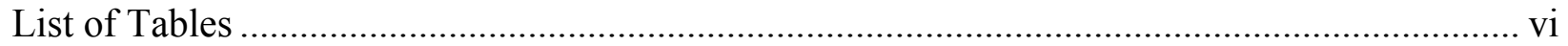

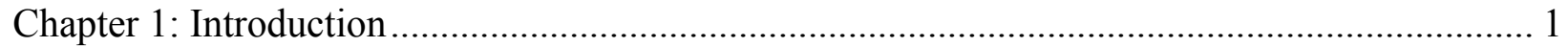

Chapter 2: Literature Review .................................................................................... 5

This chapter describes the current conceptualization of flourishing, including its history, measurement, and importance. Further, a description of mindful self-care, its model, and components will be provided. Current literature surrounding resilience, including its components, measurement, and importance is also presented. Finally, the framework for the

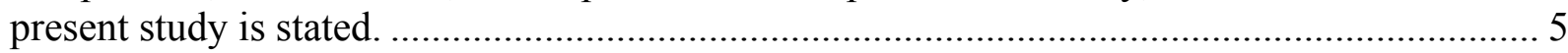

Flourishing: History, Measurement, and Importance .................................................. 5

A Brief History and Overview of Flourishing ............................................................ 5

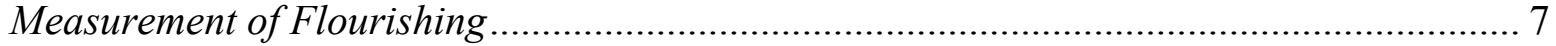

Importance of Flourishing ....................................................................................... 8

Mindful Self-Care: Definition, Model, and Components ...................................................... 9

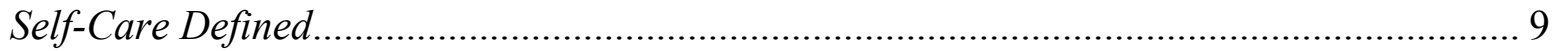

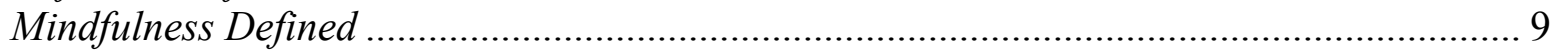

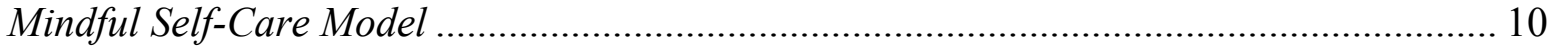

Physical Care as a Component of Mindful Self-Care ...................................................... 11

Supportive Relationships as a Component of Mindful Self-Care ...................................... 12

Mindful Awareness as a Component of Mindful Self-Care ............................................... 13

Self-Compassion as a Component of Mindful Self-Care .................................................. 13

Sense of Purpose as a Component of Mindful Self-Care ...................................................... 14

Mindful Relaxation as a Component of Mindful Self-Care ................................................ 15

Supportive Structure as a Component of Mindful Self-Care ........................................... 16

Resilience: Definition, Components, Measurement, and Importance ................................... 17

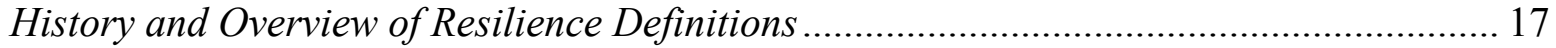

Components of Resilience ................................................................................................... 24

The Measurement of Resilience and the Three-Factor Model........................................... 26

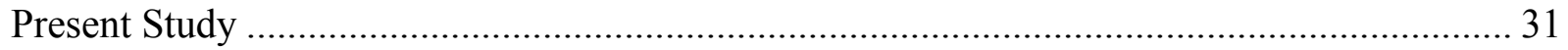

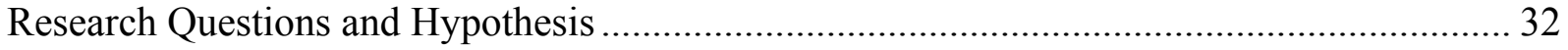

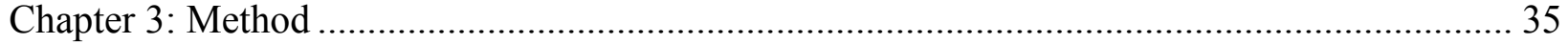

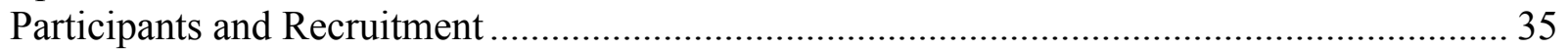

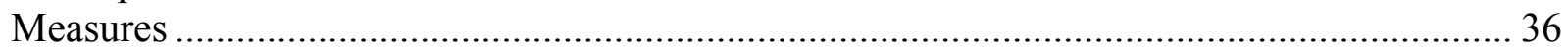

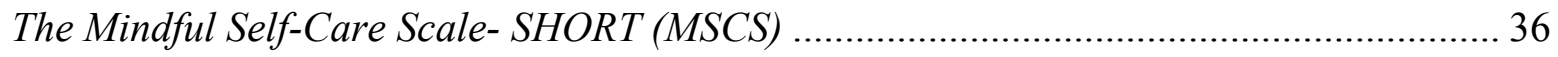

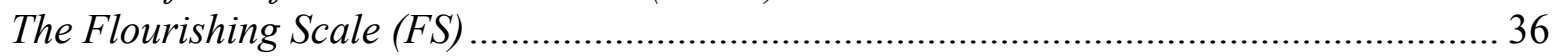

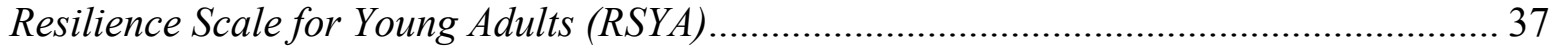

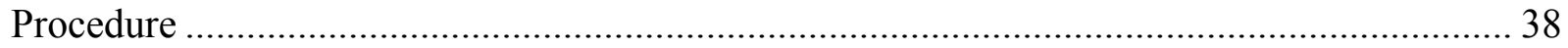

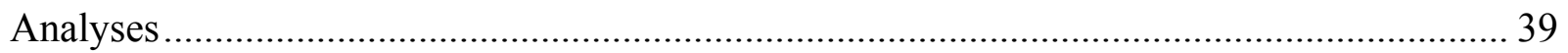

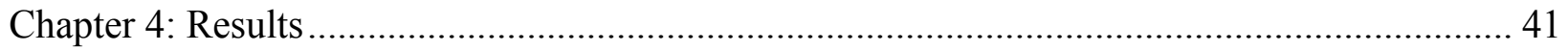

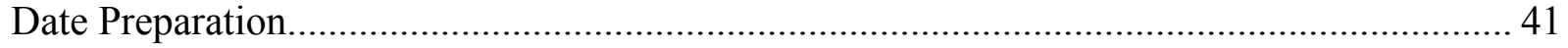

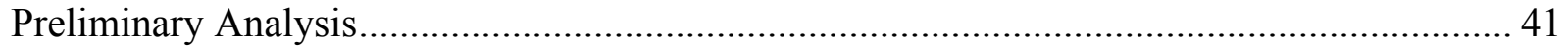

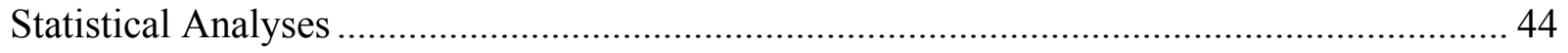




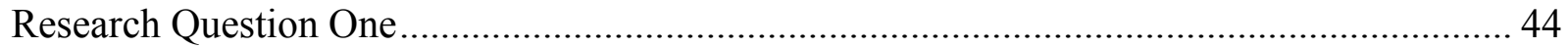

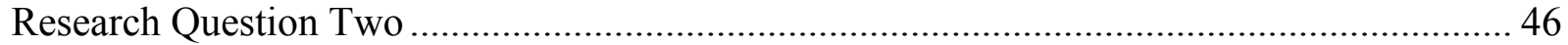

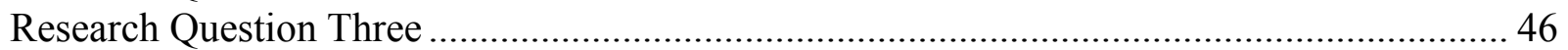

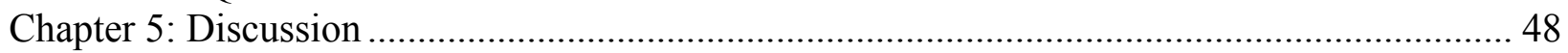

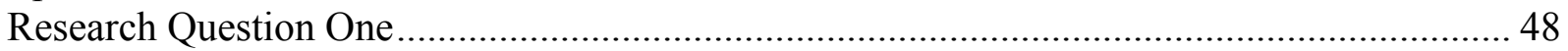

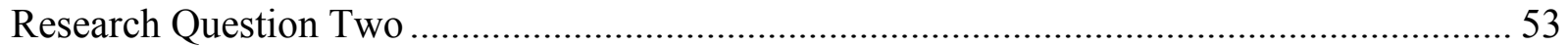

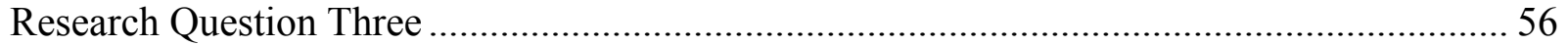

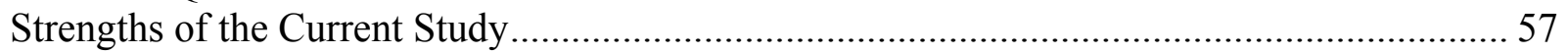

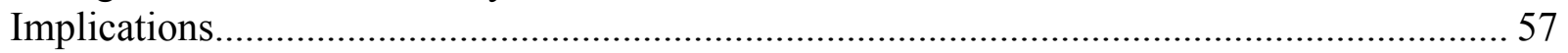

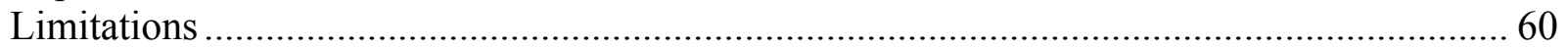

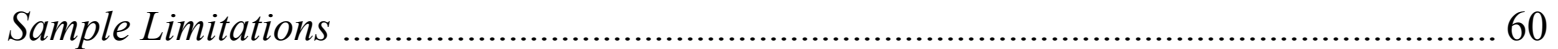

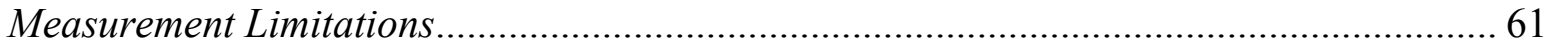

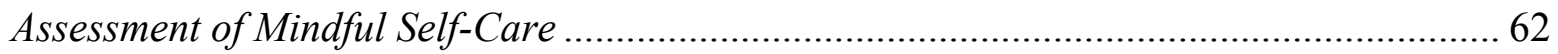

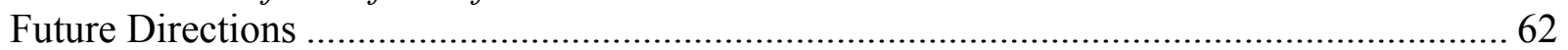

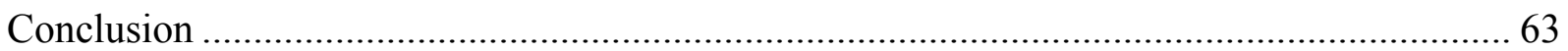

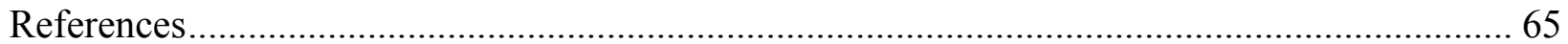

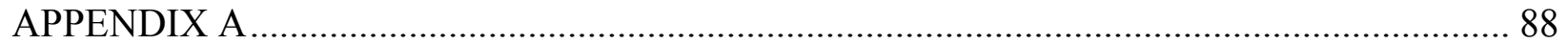

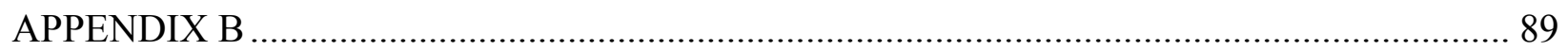

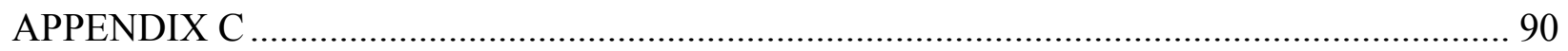

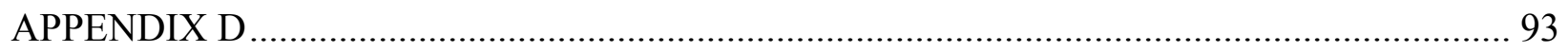




\section{List of Tables}

Table 1. Internal Consistencies ....

Table 2. Descriptive Data for the MSCS and RSYA measures .............................................. 43

Table 3: Correlation Matrix among Dependent and Independent Variables .............................. 44

Table 4. Mindful Self-Care Predicting Levels of Flourishing .............................................. 45

Table 5. Resilience Predicting Levels of Flourishing ........................................................ 46

Table 6. Regression Analysis for Resilience Predicting Flourishing beyond Mindful Self-Care 47 


\section{Chapter 1: Introduction}

In $2016,69.7 \%$ of Canadian students who graduated high school subsequently enrolled in post-secondary education (Statistics Canada, 2016). Enrolments in Canadian colleges and universities have been steadily increasing since the early 2000s due to the changing labour market and the shift towards post-secondary educational requirements in the labour force (Statistics Canada, 2016). The benefits of investing in a post-secondary education have been well documented; both the private and public sectors are looking to maximize potential skills and abilities of individuals (Tomkowicz \& Bushnik, 2003). Completing post-secondary education and moving into a career related field is believed to result in social, economic, and personal returns from investing in a post-secondary program (Tomkowicz \& Bushnik, 2003). Given the importance of post-secondary education to today's youth, understanding the risks, stressors, and rewards of this transition time is beneficial. Attending a post-secondary institution has numerous personal and social benefits. Completing higher education can lead to higher income, better health, less stress, and better job security (Oreopoulos \& Salvanes, 2011). However, it has been shown that the post-secondary student population are also faced with the increased risk of stress and psychological disorders (Auerbach et al., 2016). The first year of post-secondary studies may be a particular critical period due to the stress, adjustment, and expectations. These challenges are reflected in the increasing rate of students leaving post-secondary studies prematurely (Statistics Canada, 2011).

Problems pertaining to well-being impacting student dropout have been recognized in many countries. The Youth in Transition Survey (2011) from Statistics Canada revealed that one in seven first-year students drop out of their university program and the number rises to one in six when accounting for all undergraduate students (Statistics Canada, 2011). In the U.S., over 
$40 \%$ of students fail to earn a bachelor's degree within six years (Velez, 2014). There are significant financial costs caused by university dropouts. A report estimated loss of $\$ 3.8$ billion in lifetime income traceable to dropouts from a single student cohort, and a related loss of potential government tax revenue of $\$ 730$ million has been shown in the research (Johnson, 2012).

Student dropout in the first year of post-secondary education can be attributable to emergent stressors. The transition to post-secondary education presents many challenges, such as moving away from home, establishing new friendships, academic stress, and financial burden (Galatzer-Levy, et al., 2012; Hicks \& Heastie, 2008). As the number of stressful life events increase for students, mental and physical symptoms also increase (Haines et al., 1996; Zaleski et al., 1998). Additionally, students who experience poor mental and physical health are at a greater risk for poor academic performance, thus increasing academic stress and perpetuating a cycle of stress and compromised health (Eisenberg et al., 2009; Haines et al., 1996; Ward et al., 2000). According to the American College Health Association - National College Health Assessment (2016), over 60 percent of post-secondary students reported experiencing more than average stress or tremendous stress within the last 12 months. Fifty-three percent of students reported anxiety and/or depression as a factor affecting academic performance in post-secondary education (American College Health Association, 2016).

The importance of actively confronting and reducing signs of stress that post-secondary education brings is vital to the prevention of psychological distress and student dropout. Factors of self-care has been shown to enhance psychological well-being through self-compassion and purpose, physical care, supportive relationships, mindful awareness, mindful relaxation, and supportive structure (Cook-Cottone \& Guyker, 2017). Self-care is defined as the daily process of 
being aware of and attending to one's basic physiological and emotional needs that includes shaping relationships, daily routines, and the environment (Cook-Cottone \& Guyker, 2017). A review of literature demonstrates that some of the major determinants of psychological wellbeing in post-secondary education includes academic workload (Mionk \& Mahmood, 1999), physical exercise (Lee \& Yuen-Loke, 2005), and social support (Rodriguez et al., 2004). Moreover, exercise has been shown to reduce stress and promote self-esteem and longterm cognitive well-being, all of which are important in the transition to post-secondary education (Leary \& DeRosier, 2012). Thus, engaging in self-care should increase levels of flourishing as it pertains to supportive structure, physical care, and supportive relationships. Flourishing includes the experience of positive emotional well-being such as positive affect (e.g., positive emotions and high life satisfaction), positive psychological functioning (e.g., selfacceptance, personal growth, purpose in life, and autonomy), and positive social functioning (e.g., social acceptance and actualization). Flourishing focuses on both affective and social component of well-being as opposed to subjective well-being which focuses on just the affect.

Research supports the existence of a number of self-care factors that are associated with positive outcomes related in flourishing in the face of adversity. Taking care of yourself helps keep your mind and body primed to deal with situations that require resilience, as shown in the research linking self-care factors with physical health and emotional well-being (Leary \& DeRosier, 2012). Resilience is the process of adequately responding to and adapting in the face of adversity (Masten, 2001). This may serve as a protective factor in post-secondary transition. A plethora of research has found that the ability to be resilient contributes to overall well-being (Allan et al., 2014; Galatzer-Ievy et al., 2012; Hartley, 2011; Johnson et al., 2015; Stack-Cutler et al., 2015). Additionally, resilience has been described as a dynamic process involving an 
interaction between the individual and the environment (Masten, 2015; Prince-Embury et al., 2016). MacDonald and Validivieso (2000) propose that by providing opportunities and emotional support to students, educational environments can promote resilience and in turn improve psychological well-being. For example, providing the opportunity for regular exercise confers resilience through positive psychological and physiological benefits that blunts stress reactivity (Silverman \& Deuster, 2014). Thus, resilience may explain some of the relationship between self-care and flourishing.

The current thesis is divided into a literature review, method, results, and discussion sections. The literature review begins with an overview of the construct of flourishing. This consists of the history of academic research into flourishing, how flourishing is measured, and the importance of flourishing to first-year post-secondary students. This follows with a section summarizing the relevant literature of mindful self-care. It consists of an introduction to commonly used definitions and models of self-care, a description of mindful self-care, and the components of mindful self-care. Finally, the history of academic research into resilience, a summary of the current definitions and conceptualizations of resilience, the importance of resilience to first-year post-secondary students, as well as a summary of the components of resilience and how it is measured is presented. To conclude the literature review, an overview of the present study, its research questions, as well as the methods for conducting the study are summarized. Following the literature review, the methods section describes the participants, measures, procedures, and statistical analyses utilized in this study. The results describe the findings of these analyses, with a discussion following an interpretation of these results, their implications, limitations, possible follow-up research, and a conclusion. 


\section{Chapter 2: Literature Review}

This chapter describes the current conceptualization of flourishing, including its history, measurement, and importance. Further, a description of mindful self-care, its model, and components will be provided. Current literature surrounding resilience, including its components, measurement, and importance is also presented. Finally, the framework for the present study is stated.

\section{Flourishing: History, Measurement, and Importance}

\section{A Brief History and Overview of Flourishing}

Understanding the historical background to the study of well-being is necessary to understand flourishing. Two approaches to well-being emerged: the hedonic tradition, which frames well-being as positive emotions and that a good life is measured by feeling good or experiencing more moments of good feelings (Keyes, 2010) and the eudaimonic tradition, which frames well-being as a way of doing things in the world and that a good life is measured by how well individuals cultivate their abilities to function well (Keyes, 2010). Fourteen facets of hedonic and eudaimonic well-being have been revealed over the years. Happiness, interest in life, and life satisfaction represent facets of emotional well-being that are highlighted in the hedonic approach (Keyes, 2010). The remaining 11 facets represent the eudaimonic approach that includes social well-being and psychological well-being (Keyes, 2010). Despite the differences in the frameworks, most researchers now believe that well-being is a multidimensional construct.

Bradburn's (1969) research on psychological well-being was an early attempt to define well-being. Bradburn theorized that psychological well-being is composed of two distinct subjective feeling states: positive and negative affect (Bradburn, 1969). One's overall sense of 
psychological well-being is a function of the difference between one's levels of positive and negative affect (Bradburn, 1969). The emphasis on positive and negative affect has been central to the work of Diener and Suh (Dodge et al., 2012). Bradburn's work marked a move from the diagnosis of a mental illness to the study of psychological reactions of ordinary people in everyday life (Dodge et al., 2012).

Ryff (1989) criticized Bradburn's work for not defining the basic structure and aspects of psychological well-being and extended Carl Rogers work to define psychological well-being in terms of core dimensions. Carl Rogers discussed well-being in terms of the good life; his belief was that each individual strives towards becoming a fully functioning person open to experience and trust (Rogers, 1961). Ryff (1989) converged multiple frameworks of positive functioning that leads to a "fully functioning person" to generate a multi-dimensional model of well-being. These dimensions include self-acceptance, personal growth, purpose in life, environmental mastery, positive relations with others, and autonomy (Ryff, 1989; 1995).

Recent research has placed an emphasis on positive functioning because psychiatry has adopted a restricted view of well-being as an absence of distress and dysfunction (Dodge et al., 2012). Several mental disorders appear to be increasing in the post-secondary student population. Measuring positive mental health may be essential for understanding transitioning students' adjustment to this period. Positive mental health is " ... a state of successful performance of mental function, resulting in productive activities, fulfilling relationships with people, and the ability to adapt to change and cope with adversity" (p. 4). Keyes brought together the hedonic view of well-being and eudaimonia view of well-being in his view of mental health (Dodge et al., 2012). To flourish means to have good mental health, and includes the presence of high levels of social, psychological, and emotional well-being (Keyes, 2002). Social well-being 
reflects our functioning when we are a member of a larger group, whereas psychological wellbeing reflects our functioning when we are in our own private, personal, and intimate sphere of life (Keyes, 2010). A person who is high in psychological well-being views their personality positively, have a sense of direction, and like the person that they are becoming (Keyes, 2010). Emotional well-being is a state of positive feelings (e.g., cheerful, extremely happy) in the absence of negative feelings (e.g., hopeless; Keyes, 2002). Research indicates that flourishing individuals are resilient, productive, and experience a high level of positive emotions (Keyes, 2002).

The absence of positive mental health is described as languishing (Keyes, 2002). Individuals who feel empty and who have lows levels of social, psychological, and emotional well-being are considered to be languishing. Individuals who are languishing have high emotional distress, limitations in their daily activities, and miss more work days (Keyes, 2004).

\section{Measurement of Flourishing}

To capture all the components of flourishing in a brief scale, Diener and colleagues (2009) created the Flourishing Scale (FS). The FS was designed to measure social-psychological prosperity, which is based on the attainment of certain universal human psychological needs (i.e., purpose in life, the need for social relationships, feelings of competence, and self-acceptance) as informed by humanistic psychology. The FS complements existing measures of subjective wellbeing, as well as assesses positive and negative feelings (Diener et al., 2010). Additionally, Diener and colleagues (2009) also incorporated into social-psychological prosperity, Ryff's (1989) idea of purpose and meaning, which is important in positive functioning. The components on the FS have significant impact on personal and psychological well-being in young adults, which makes it a good fit for this study (Diener et al., 2009; Ryan \& Deci, 2010). Students who 
experience higher flourishing would score higher on the scale, whereas students with a lower score, may be languishing.

\section{Importance of Flourishing}

Research has supported the hypothesis that anything less than complete mental health results in increased impairment and disability (Keyes, 2002; 2007). Adults who are flourishing functioned superior to others in terms of fewer missed work days, fewer cutbacks at work, lower levels of health limitations, fewer chronic health conditions, and highest levels of psychosocial functioning (Keyes, 2007). In terms of mental well-being, flourishing adults reported the lowest level of perceived helplessness, highest level of functioning goals (e.g., knowing what they want in life), and higher levels of happiness (Keyes, 2007). In an academic setting, there is evidence to suggest that students who thrive and flourish demonstrate stronger academic performance (Suldo et al., 2011). For example, a study by Suldo and colleagues (2011) found that students with higher well-being demonstrated the highest grades and lowest rates of school absences one year later. Moreover, Howell (2009) found that students who were flourishing reported superior grades, higher self-control, and lower procrastination in comparison to students who were moderately mentally healthy or languishing. Thus, flourishing is a complementary goal with academic development.

In summary, this study defines flourishing as the attainment of universal human psychological needs. Specifically, the components of flourishing include a purpose in life, the need for social relationships, feelings of competence, and self-acceptance. Research has discussed the importance of flourishing for students' physical and mental health and in turn, this may relate to self-care. Following this section is a review clarifying the definition of mindful 
self-care, followed by identifying the specific mindful self-care model used for this study. The literature review on mindful self-care closes with a brief overview of its components.

\section{Mindful Self-Care: Definition, Model, and Components}

\section{Self-Care Defined}

Self-care has been defined in various ways throughout the literature. Pincus (2006) defined self-care as something one does to improve the sense of positive subjective well-being. Through utilizing qualitative methods (i.e., narrative interviews), there have been various definitions of self-care (Lozito, 2018). For example, researchers have reported that self-care is the overall act of one caring for themselves (Lozito, 2018), while other researchers have defined self-care in terms of activities that constitute self-care with themes such as physical (Carrol et al., 1999; Mahoney, 1997), psychological (Norcross, 2000), spiritual (Valente \& Marotta, 2005), and support (Carrol et al., 1999; Guy, 2000). Combining these efforts to define self-care, Myers and colleagues (2012) stated that self-care involves engagement in behaviours that maintain and promote physical and emotional well-being and may include factors such as nutrition, exercise, sleep, social support, and mindfulness practice.

\section{Mindfulness Defined}

Mindfulness has its roots in the Eastern religious traditions practice of mindful meditation (Shapiro et al., 2012). However, mindfulness is more than meditation, it is a state of consciousness which involves attending to one's moment-to-moment experience (Brown \& Ryan, 2003). Meditation is the scaffolding used to achieve the state of mindfulness (Kabat-Zinn, 2003). The three fundamental building blocks of mindfulness are intention, attention, and attitude (Shapiro et al., 2012). Intention is one's personal vision and is often dynamic and evolving (Freedman, 2005). For example, a stressed undergraduate student may begin 
mindfulness practice to reduce tension. As the student's mindfulness practice continues, an additional intention of relating more kindly to peers may develop. Attention is the observation of one's moment-to-moment internal and external experience (Shapiro et al., 2012). This includes many different aspects of attention such as the capacity to attend for long periods of time to an object; the ability to inhibit secondary processing of feelings, thoughts, and processes; and the ability to shift attention between objects (Shapiro et al., 2012). Attitude is the qualities one brings to the attention. In mindfulness, the aim is to learn to attend to internal and external experiences without evaluation and practice acceptance and kindness (Shapiro et al., 2012).

Researchers began to integrate mindful awareness - attention to one's internal needs and external demands - into the working definition of self-care (Christopher \& Maris, 2010; CookCottone, 2015). Mindful self-care is an integration of mindfulness and intentional engagement of practices of self-care that serves one's well-being and personal effectiveness (Cook-Cottone, 2015). For the purposes of this paper, the definition of mindful self-care is used.

\section{Mindful Self-Care Model}

Mindful self-care follows the attuned representational model of self (ARMS) as a system integrating internal experiences (i.e., physiological, emotional, and cognitive) and external experiences (i.e., familial, community, and culture; Cook-Cottone, 2015). The internal and external aspects are interconnected by a process called attunement (Cook-Cottone, 2017). Attunement is defined as a reciprocal process of mutual influence and co-regulation (CookCottone, 2015). An individual must maintain positive attunement and regulation with each aspect of the internal experiences and engage effectively across each of the external domains (CookCottone, 2015). For example, an individual is able to nurture an awareness and maintenance of the needs of the inner aspect of self, while engaging within the context of family, community, 
and culture. In the transition to post-secondary education, influences from the internal system (e.g., being a perfectionist) and/or the external system (e.g., getting a failing grade) can contribute to misattunement. When this misattunement happens, individuals may view the external pressure as true and the inner self feels defeated. Engaging in mindful self-care allows the individual to balance the external pressures by attending to one's inner experience. Aspects of mindful self-care as described by Cook-Cottone (2015) are physical care, supportive relationships, mindful awareness, self-compassion, purpose, mindful relaxation, and supportive structure.

\section{Physical Care as a Component of Mindful Self-Care}

Physical care includes both exercise and nutrition that has been shown to affect positive well-being. Physical exercise is active muscle exertion involving small or large areas of muscle mass that promotes blood flow, this could include playing sports, dance, or walking. Research has shown that the transition to university is associated with increased physical health problems (Gall et al., 2000). It has been shown that students who have a decreased level of physical fitness during their first year of university, also experienced high stress (Steven et al., 2006). In a study by Roth and Holmes (1987), the researchers trained students who reported high levels of stress to become physically fit. After an 11-week fitness program, students improved in their aerobic fitness levels and depression scores (Roth \& Holmes, 1987). It is unsurprising then that exercise is associated with decreased negative affect and increased positive affect (Bray \& Born, 2004). Within college, those who meet recommendations for physical activity are less likely to report poor mental health, and perceived stress in addition to reporting more positive mood states (e.g., decreased fatigue and tension; Bray \& Born, 2004). 
Furthermore, nutrition affects an individual's physical and mental health. University students who live away from home may engage in unhealthy eating behaviour because of the hurried lifestyle (Barker \& Galambos, 2007). Studies have shown a positive relationship between life satisfaction and healthy food choices (Schnettler et al., 2013). This association is from the pleasure of eating tasty food with nutritional aspects and social and psychological aspects (Schnettler et al., 2013). Since attending to your physical health is important in maintaining mental health, it is often included in the definition of self-care, including Cook-Cottone's mindful self-care definition.

\section{Supportive Relationships as a Component of Mindful Self-Care}

In some cases, the transition to university requires leaving home, family, and friends, resulting in a significant disruption of an individual's support system. Supportive relationships with parents, friends, and school are positively linked with academic success and socialemotional well-being (Wang \& Eccles, 2012). Specifically, family support is linked to happiness (Delle Fave et al., 2010) and emotional support has been shown to be a protective factor in the face of adverse experiences (Hsu, 2010). Leaving the family home results in reduced direct dependence on parents and other members of that individual's established social system which can increase feelings of isolation (Delle Fave et al., 2010). Lack of supportive relationships among college students is one of the determinants of psychological problems (Rodriguez et al., 2004). Having supportive relationships has been described as a buffer against life stressors and a factor that promotes health and wellness (Dollete et al., 2004). Supportive relationships can include family, friends, teachers, community, or any other social groups that the individuals are affiliated with. Since support from family, friends, and significant others have been found to 
reduce the impact of psychological problems among students, it is included in the definition of mindful self-care (Cook-Cottone, 2015).

\section{Mindful Awareness as a Component of Mindful Self-Care}

Mindful awareness is a term used to describe an enhanced awareness of and attention to current experience or present reality (Brown \& Ryan, 2003). The opposite of mindful awareness can be thought of as a state of mindlessness or less "awake" states of automatic functioning that may be chronic for many individuals (Brown \& Ryan, 2003). Thus, mindful awareness can be important in disengaging individuals from automatic thoughts and unhealthy behaviour patterns that plays a key role in psychological problems. Open awareness is valuable in facilitating the choice of behaviours that are consistent with one's needs, values, and interests important for selfcare (Ryan \& Deci, 2001). Mindfulness facilitates flourishing through fulfillment of the basic needs and values such as competence and relatedness (Hodgins \& Knee, 2002). Additionally, being able to regulate your attention has been shown to benefit physical and mental health, reduce stress, and facilitate emotion regulation (Delgado et al., 2010; Wadlinger \& Isaacowitz, 2011).

\section{Self-Compassion as a Component of Mindful Self-Care}

Self-compassion is often a related concept in the discussion of self-care. It is described as one's own suffering, caring for oneself, accepting one's flaws, and recognizing that experience as common (Neff, 2003). This allows the individual to have a more accurate view of themselves. Self-compassion is rooted in social mentality theory that proposes a threat system, which includes feelings of security and defensiveness, and a self-soothing system involving safety and secure attachment (Neff, 2003). Engaging in self-compassion promotes a sense of security and emotional calmness by activating the self-soothing system and deactivating the threat system 
(Neff, 2003). Self-compassion has been shown to alleviate depression, anxiety, and stress (Leary et al., 2007; Neff, 2003). Higher levels of self-compassion have also been shown to be associated with life satisfaction, social connectedness, psychological strengths, such as happiness, and reduced self-criticism (Germer, 2009; Neff et al., 2007). By allowing an individual to self-sooth, self-compassion can contribute to a student's well-being and ability to successfully cope with the environment. Self-compassion is an approach in self-care with a potential to assist students in managing challenges that accompany first year of university.

\section{Sense of Purpose as a Component of Mindful Self-Care}

First year undergraduate students must navigate goals or a purpose salient to the transition to post-secondary education. Frankl (1963) stated that when one develops a sense of purpose, it generates action towards a purposeful life such that one is focused on contributing to the world and empowering the person to persist even in the most challenging circumstances. Expanding on Frankl's idea of a sense of purpose, Hanlon (1968) noted that without education, self-actualization may not be achieved. Self-actualization is when an individual builds awareness of a world view, then visualizes themselves within that worldview, creating goals, motivation, organization, and perseverance to reach that identified self (Hanlon, 1968). For example, a firstyear undergraduate student enters university with the perspective of becoming a surgeon. The student will visualize themselves as a surgeon (e.g., wearing a surgeon's mask, working with patients in the hospital). Having this vision and a sense of self would help the student establish a sense of purpose in their education (Hanlon, 1968). As Erikson (1963) noted, young and middleaged adults develop a sense of purpose through establishing a stable identity, forming intimate relationships, and being productive and creative. Fulfilled purpose gives a sense of contentment and the feeling of having an achieved sense of security as described with self-compassion (Reker 
et al., 1987). However, without a sense of purpose, an individual would experience boredom and distress or anxiety (Frankl, 1963). Individuals find a purpose in three primary ways: 1) by doing something of personal significance while engaged in work, school, or other daily activities, 2) by experiencing or encountering something or someone, 3) by coping with and overcoming suffering (Frank1, 1963). Young adults have a strong need to achieve new goals by engaging in school such as going to university so they can look toward future work potentialities (Erikson, 1963).

\section{Mindful Relaxation as a Component of Mindful Self-Care}

The relaxation response occurs when the body is no longer in perceived danger and the autonomic fight-or-flight response system returns to normal (Benson, 1993). During times of acute stress, the relaxation response moves the body from psychological arousal (e.g., increased heart rate and blood pressure, increased hormonal activity, and slowed digestive function) to a state of psychological relaxation (e.g., heart rate, blood pressure, hormonal activity, and digestive function returns to their normal state; Benson, 1993). A wide array of available techniques for mindful relaxation emerged as various relaxation techniques precipitated the relaxation response and thereby reduced stress and improved overall well-being (Nelson, 2016). Some common mindful relaxation techniques include progressive muscle relaxation, guided imagery, and simple diaphragmatic breathing (Nelson, 2016). The act of diaphragmatic breathing is fundamental to most forms of relaxation (Fried \& Grimaldi, 1993). Diaphragmatic breathing, also known as abdominal, belly, or deep breathing is characterized by the expansion of the abdomen when inhaling (Nelson, 2016). Stress often cause individuals to engage in shallow (i.e., chest or thoracic) breathing, which increases carbon dioxide levels in the blood and decreases oxygen levels, causing hyperventilation (Fried \& Grimaldi, 1993). The ability to control your stress 
through diaphragmatic breathing is an increment of self-efficacy (Stice et al., 2006). Engaging in diaphragmatic breathing creates an awareness of the tension already possessed within the individual as well as their ability to volitionally control it, increasing perceived self-efficacy (Nelson, 2016). The mindfulness relaxation techniques are a simple psychological treatment that reduces anxiety and depression. By practicing mindfulness relaxation techniques, tension is ameliorated, psychological relaxation is induced, and unnecessary rumination is decreased as the techniques serve as a distraction (Nelson, 2016; Smith et al., 1996).

\section{Supportive Structure as a Component of Mindful Self-Care}

During the transition to university, students exchange the safe, secure, and more structured home and school environment for an autonomous and less supportive school environment (Kotze \& Kleynhans, 2013). Supportive structure consists of practices aligned with the external experience of self that provides a framework for balancing external demands (Cooke-Cottone, 2017). This includes keeping study or work areas organized, maintaining a comfortable and pleasing living environment, creating a balance between the demands of others and an individual's own needs, and maintaining a manageable schedule. Being able to maintain a healthy living, study, and work environment and a schedule that allows for sufficient rest and restoration are constructs believed to play a role in well-being (Cappuccio et al., 2011; CookCottone, 2015). An unsupportive post-secondary environment can create mixed feelings and apprehensions in the students' learning environment that may impact their emotional health or well-being (Christie et al., 2008). However, a supportive learning environment that is studentcentred can in turn enable the students to have a constructive learning experience (Christie et al., 2008). Connected to the idea of finding a purpose in university, when students feel their 
environments are supportive, they search for meaning or purpose, and meaning seeking is more enjoyable and more successful (Shin \& Steger, 2016).

Mindful self-care is seen as the foundation required for well-being in a school setting by preventing and decreasing symptoms associated with mental illness, preventing and decreasing burnout, and improving productivity (Cook-Cottone, 2015). When students are engaging in mindful self-care, they are aware and accepting of whatever is arising in their own physical and mental processes in a nonjudgmental way and use the insights gained to act with clarity (Epstein, 1999). This allows individuals to recognize what they need before it interferes with academic success and mental health.

In summary, this study defines mindful self-care as the ability to balance external pressures by attending to one's inner experience through physical care, supportive relationships, mindful awareness, self-compassion, purpose, mindful relaxation, and supportive structure. The mindful self-care model follows the ARMS, which is a system that integrates internal and external experiences (Cook-Cotton, 2015). Research has discussed the importance of mindful self-care in a school setting by preventing and decreasing symptoms associated with mental illness and burnout. Following this section is a review clarifying the definition of resilience, followed by identifying the specific model used and its components. The literature review on resilience closes with a presentation on how to measure resilience and its importance.

\section{Resilience: Definition, Components, Measurement, and Importance}

\section{History and Overview of Resilience Definitions}

There has been a lack of consensus in regard to a definition of resilience. The difficulty in defining resilience is that it is dynamic and multidimensional. Early research on resilience adopted a pathogenic-based approach, defining resilience as low levels of distress symptoms 
(Casella \& Motta, 1990). Recently, resilient research has focused on the capacities for successful adaptation (Kimhi \& Eshel, 2015). Most researchers who study resilience recognize it as an individual's ability to thrive in the face of adversity, to adapt to a challenge, or recover after experiencing an acute stressor (Masten, 2014). A simple definition of resilience is "positive adaptation in the context of adversity (Masten, 2014). At the most basic level, resilience involves two judgements: 1) the degree of risk or adversity present and 2) how well an individual is functioning during or after risk or adversity (Masten, 2014). If an individual experiences risk or adversity and is resuming efficient functioning relatively well during or after this risk, then the individual is displaying resilience. Resilience is identified as a personal resource that helps people stay clear of or bounce back from negative emotional experiences, ranging from mild anxiety at school to trauma and general depression (Tugade \& Fredrickson, 2004). This lens on resilience shifted from a focus on assessing risk or adversity, towards concentrated efforts to enrich strength or capability (Panter-Brick \& Leckman, 2013).

Resilience research has its origin in the aftermath of the World War II (Masten, 2014). Many of the pioneering researchers of resilience were directly affected by the war as refugees, survivors of bombing campaigns, or as soldiers (Masten, 2014). This led to understanding of resilient children who grew up in poverty, dysfunctional families, or in conditions of cultural deprivation (Agaibi \& Wilson, 2005). Extending the resilience research beyond war and trauma, studies looked at risk factors and mental health in children. Some of the early research into resilience focused on studying children whose parents suffered from schizophrenia (Garmezy, 1974). Even though having a parent with schizophrenia increased the probability of a child eventually developing schizophrenia, many of the children went on to lead productive lives (Garmezy, 1974). In the 1960s, researchers found that in spite of the presence of risks, most 
individuals do not develop psychopathology and thus, resilience has been described as a phenomenon in which children who grew up in adverse environments flourished (Anthony, 1974; Garmezy, 1974). Researchers found that in spite of the presence of risk, most individuals developed normally (Masten, 1998). It became clear that it was as important to predict and understand health and wellness in the presence of risk and so, resilience was referred to as good developmental outcomes despite high risk, sustained competence under stress, and recovery from trauma (Werner, 1995).

Although there is no widely accepted definition of resilience, this does not question the validity of the research as these definitions share commonalities. Aburn and colleagues (2016) identified five key definitions that adequately categorized most definitions used by different researchers. The first being, resilience as a process of overcoming adversity and rising above the challenges faced in a time of crisis or trauma (Ungar, 2008; Werner \& Smith, 1982). Some definitions include a process of overcoming adversity while avoiding negative outcomes (Garmezy, 1991; Werner \& Smith, 1982) and the capacity to persist and move pass hardship (Longenecker et al., 2011). Additionally, words such as "flourishing", "thriving", and "succeeding" were also used and relate closely to the notion of overcoming adversity in times of stress (Aburn et al., 2016). When faced with a challenge, the focus is on the presence of positive outcomes and the absence of negative outcomes. In this definition, resilient students who are transitioning to post-secondary education will show many positive outcomes, such as flourishing, good academic performance, positive relationships, while avoiding negative outcomes such as high levels of stress and poor mental and physical health. However, this definition does not take into account individuals who have been impaired but return to a normal level of functioning. The ability to adapt or adjust is a key component of resilience (Aburn et al., 2016). 
The second definition addresses the limitation of the first definition of resilience by including adaptation and adjustment after trauma or adversity (Cummings et al., 2000; Montpetit et al., 2010). Some examples include adaptation and growth despite exposure to significant stressors (Hegney et al., 2007) and adjustment to diverse circumstances and the ability to enhance competence in conditions of adversity (Mansfield et al., 2012). These definitions focus on the ability to cope after challenges. However, there is an issue with how to define adjustment or adaptation. The definition of adjustment or adaptation depends on culture and context in which the adversity is experienced. For example, in many Asian cultures, remaining in the family home into adulthood is acceptable, whereas in some Western cultures, remaining in the family home may be viewed as a failure to establish independence. Thus, an individual may be considered resilient if he or she moves out of the family home for post-secondary education. Moreover, the definition of positive adaptation or adjustment after trauma does not taken into account trauma or adversity that can be permanent. An individual can still show resilience in the face of chronic health issues or irreversible loss.

The third definition of resilience addresses overcoming chronic adversity. Edward and colleagues (2009) highlights that the word resilience originates from the Latin word "resiliere" meaning to jump back and this holds meaning for many situations. The link between recovery and bouncing back is being able to recover from a trauma and returning to baseline well-being (Garmezy, 1991). An example of this definition is to "bend, but not break," and acknowledge that adaptability is more important than hardiness (Longenecker et al., 2012). This definition of resilience includes individuals who return to a normal level of functioning after impairment. In post-secondary education, students may initially struggle, but can eventually return to normal functioning, demonstrating resilience. 
The fourth definition addresses an absence or lower incidence of mental health issues for determining whether an individual is resilient (Burns \& Anstey, 2010; Rutter, 1987). In this context, researchers treat the absence of psychological disorders as a proxy for resilience (Aburn et al., 2016). Some studies describe resilience and vulnerability as a continuum, with resilience representing resistance of psychopathology (Everall et al., 2006). Similar to immunity gained from a healthy lifestyle, resilience can be described as mental immunity (Aburn et al., 2016). Individuals transitioning to post-secondary education who do not develop negative mental health consequences are demonstrating resilience. The ease of operationalization is a clear strength of this approach, as one can use rating scales measuring positive mental health, anxiety or depression, post-traumatic stress disorder symptoms, and affective disorders to assess an individual's level of resilience (Aburn et al., 2016). However, this definition excludes factors associated with well-being or flourishing, such as negative and positive affect as well as satisfaction in one's relationships and career.

The final definition encompasses resilience as an ordinary phenomenon grounded in ordinary things, such as family, love, and friendships (Aburn et al., 2016). Masten (2001) highlighted the importance of positive experiences in contributing to an individual's resilience. Some examples include resilience defined as a common phenomenon that results in most cases from basic human adaptation systems (Masten, 2001), and "ordinary magic" happens when responding to adversity becomes part of their lives (Janssen et al., 2011). This suggests that when an individual's ordinary adaptational system is malfunctioning, their resilience is lacking. The personal strength gathered from previous adverse experiences or trauma and the support from families and friends is critical to being resilient. This definition of resilience views most students demonstrating resilience in the challenges posed by higher education through their typical 
adaptational systems, including social structures such as the school community, their tenacity and persistence, their emotional intelligence and the ability to tolerate stress, and their drive to establish positive acceptance of change (Hartley, 2011).

Life transitions, such as starting post-secondary studies, starting a family, beginning a career, and relocating are all challenges that require adaptation and adjustment to the new and stressful event. Although many researchers have focused on studying resilience in individuals who experience exceptional adversity, some has focused on the role that resilience plays in more commonplace stressors. First-year undergraduate students experience challenges and stressors that are inevitable in life, making resilience commonplace in post-secondary education. The definition of resilience as arising from ordinary adaptational systems is used in this study because although the challenge in this transition may not be severe adversity, the need to respond to high levels of stress is clear. This definition appreciates the challenges posed by postsecondary education as stress and changes are part of the transition from high school to postsecondary education.

There are several themes that are common across most conceptualizations of resilience, such as the dynamic and contextual nature of resilience (Aburn et al., 2016). The demonstration of resilience may vary in differing environments and with different support networks (Aburn et al., 2016). For example, a student can show great success in starting a career, but struggle in the transition to post-secondary education. Additionally, individuals can show perseverance, strength, and ability in one area, but struggle in another. For example, a student may be able to form healthy and supportive relationships, but struggle in their academic coursework. Resilience is not static; an individual may show resilience at different points in their life (Gartland et al., 
2011). A student can initially struggle during the transition to post-secondary education but can flourish later in their education.

Other common themes across definitions include recovery and sustainability (Reich et al., 2010). Recovery is the ability to rebound or adapt after a stressful event. Recovery in postsecondary education can be the natural capacity to manage stress levels and return to a more positive mood, demonstrating recovery. On the other hand, sustainability is revealed by perseveration of energy and commitment to purposeful engagements in school under the adaptation of challenges imposed by post-secondary education (Reich et al., 2010). Thus, the same student who shows sustainability will manage their stress and positive mood over time, avoiding relapse. This theme of recovery and sustainability is consistent across most conceptualizations of resilience.

In summary, there is no widely accepted definition of resilience, although all definitions involve the capacity to function in the presence of stress or adversity. These definitions emphasize overcoming challenges, the ability to adapt, adjustment, the ability to return to a normal level of functioning, increase levels of mental health, or the use of ordinary adaptational systems. There are common themes within these definitions including resilience as dynamic and contextual. Individuals can show differing levels of resilience at different times and in various contexts. Additionally, resilience can be displayed along a continuum ranging from small successes to extraordinary victories. In this sense, resilience refers to ordinary adaptational systems that are used to overcome various life stressors and challenges. Masten's (2001) conceptualization of resilience as developing out of ordinary adaptational systems at the most basic level, involves two judgements. The first judgment is the degree of risk or adversity present (Masten, 2001). The second is how well an individual is functioning in response to adversity 
(Masten, 2001). If a first-year undergraduate student is functioning relatively well after the transition to post-secondary education, then that individual is displaying resilience.

\section{Components of Resilience}

An issue with defining resilience is reflected by the different components that contribute to resilience. However, various factors have consistently been associated with resilience including social support, positive relationships, and spirituality (Masten, 2015). Additionally, research reports that cognitive factors such as motivation, problem-solving skills, and intelligence are associated with resilience (Crawford et al., 2006; Masten, 2015).

Several studies have found positive parenting and support to be one of the most important predictors of childhood resilience (Ellingsen et al., 2014). Parents are the first source of opportunity to nourish components of resilience in their children such as social support and positive relationships (Masten, 2015). From an ecological perspective, individual components that contribute to resilience such as problem-solving skills, emotional regulation, and social competence develop within the context of the family system, school system, and community (Prevatt, 2003).

Authoritative parents are attuned to their child's needs which helps the child to master developmental tasks that builds to more complex capacities needed to overcome significant environmental challenges (Zakeri et al., 2010). Supportive and positive relationships appear to be instrumental in helping individuals develop intrinsic resilience capacities and effective coping responses to stressors (Masten, 2001). Mota and colleagues (2016) found that teachers, coaches, and extended family members can serve as important socialization agents that predict resilience in children. In relation to post-secondary education, students who form positive relationships with course instructors and make meaningful friendships should also be more resilient. Brooms 
and Davis (2017) reported that forming positive mentoring relationships is important to staying focused in higher education. Research has shown that student-faculty interaction is associated with increased classroom engagement, sense of belonging, and willingness to take on greater challenges (Kim \& Lundberg, 2015).

Spirituality, hope, or a belief that life has meaning are also common components of resilience (Crawford et al., 2006). For individuals with trauma, spirituality may help them accept and overcome the trauma they experienced (Masten, 2014). Being part of a religious community can also provide support as well as mentorship, which has been associated with enhancing an individual's motivation to overcome their adversity (Masten, 2014). In post-secondary education, being part of a faith-based community can mitigate stress and loneliness experienced by leaving home and moving to a new environment. Religiosity has been shown to be associated with happiness and better mental health in post-secondary students (Abdel-Khalek \& Lester, 2017).

Cognitive factors such as motivation, problem-solving abilities, and intelligence are components of resilience (Masten, 2014). Motivation is the internal drive to persist in the face of challenges (Messer, 2002). On the other hand, mastery motivation is the internal drive to persist and succeed to become competent in performing challenging tasks (Messer, 2002). One component that impacts mastery motivation is self-efficacy, or the belief in one's capabilities to mobilize motivation to exert control over a given event (Bandura, 1977). Students who retain the belief that they will be able to control their success are more likely to persevere in their efforts. Self-efficacy is developed over time when completing challenging tasks making self-efficacy extrinsic, which develops from interactions with the environment (Bandura, 1977). Self-efficacy and mastery motivation lead to control over the environment and this control leads to a greater likelihood that adversity will be overcome (Masten, 2014). Self-efficacy is an important 
component in resilience for post-secondary students as students are required to complete difficult academic courses that leads to academic achievement. Self-efficacy and motivation may lead to lower levels of stress when faced with a challenging academic workload. Research has shown that self-efficacy is associated with persistence in the first year of post-secondary education (Baier et al., 2016), as well as better mental health and happiness (Abdel-Khalek \& Lester, 2017). Problem-solving and intelligence have been defined by researchers to include adaptation to the environment or adaptive behaviour (Binet, 1904; Sternberg, 1982). This is similar to resilience definitions that include adaptation. Intelligence has been shown to be more strongly associated with competence when there is adversity (Masten \& Obradović, 2006). In postsecondary education, intelligence can make completing challenging academic coursework challenges easier, reducing a major source of stress and allowing the individual to flourish.

To summarize, several components are involved in resilience such as support, positive role models, spirituality, and a belief that life has meaning. The family support system contributes to resilience through factors such as positive parenting that teaches the child more complex capacities needed to overcome significant environmental challenges (Zakeri et al., 2010). Spirituality, hope, and a belief that life has meaning allows an individual to believe in a purpose behind experiencing adversity in order to overcome the event. Additionally, cognitive components such as motivation, problem-solving abilities, and intelligence are associated with resilience in students experiencing the transition to higher education. Researchers agree that these components all strongly contribute to resilience and have operationalized resilience into measurable terms in empirical research.

\section{The Measurement of Resilience and the Three-Factor Model}


Resilience has been operationalized as an outcome, a process, and a trait (Fletcher \& Sarkar, 2013). Resilience as an outcome is the absence of symptoms and/or the presence of adaptive functioning following trauma (Happer et al., 2017). For example, students with resilience are "resistant" against the challenges associated with the transition to post-secondary education, allowing them to flourish. Resilience as an outcome takes on a protective factor model as research has shown that resilience negatively correlates with PTSD, depression, and anxiety symptoms (van der Walt et al., 2014). Based on this model, resilience operates proximally to the trauma and appears before symptoms develop. Although previous research defined resilience by post-trauma outcomes, defining resilience as an outcome following a traumatic experience fails to address the mechanism of resilience (Happer et al., 2017).

Resilience as a dynamic process is a cluster of positive resources that can be drawn as one strives to achieve positive outcomes (Sanders et al., 2015). This differs from resilience as an outcome, as it does not require individuals to be invulnerable to psychopathology, but rather able to adapt (Lundman et al., 2010). For example, a student who transitions to post-secondary education may struggle in the beginning but learn to adapt to their environment showing resilience. Resilience can increase and be impacted by intervention or treatment (Padesky \& Mooney, 2012). This model emphasizes resilience as a potential for change throughout the lifespan.

Resilience as a trait is viewed as stable and innate and can be measured through selfreport questionnaires (Happer et al., 2017). Black and Kremen (1996) define trait resilience as a quality of an individual that does not apply to a specific, one-time behaviour. A meta-analysis demonstrated that the impact of trait resilience was constant in participants ranging in age from six to 60 years old and predicted a stable prediction of mental health (Hu et al., 2015). In this 
sense, a first-year undergraduate student with higher levels of resilience prior to entering higher education will demonstrate flourishing compared to a student with lower levels of resilience at baseline. This model emphasizes that resilience is an innate trait that can be influenced by cultural and environmental factors.

Each approach to operationalizing resilience provides valuable information about how the individual addresses and responds to challenges (Maltby et al., 2015). The current study focuses on trait resilience as this maps onto Masten's (2001) definition of resilience as utilizing ordinary adaptation processes to overcome adversity. This perspective suggests that resiliency is based on fundamental systems identified as characteristics of human functioning, and that it has adaptive significance across different stressors (Prince-Embury et al., 2017). There are still debates around what measure best represents trait resilience or personal resilience. Pangallo and colleagues (2015) reviewed 17 trait resilience measures and concluded nine common themes. The common themes found in measures of resilience are mastery, self-efficacy, adaptability, active coping, positive affect, supportive relationships, hardiness, and having a structured environment (Pangallo et al., 2015). Mastery was described as a sense of control or competence in regard to life's challenges (Pangallo et al., 2015). Closely related to mastery was self-efficacy, which is the belief that one can accomplish a task. Another common theme was adaptability or the ability to adjust in difficult situations accordingly to create a positive outcome (Pike et al., 2010). Following adaptability, active coping was identified which is using one's own resources to overcome challenges (Pangallo et al., 2015). The next theme discussed was a tendency to experience positive emotions such as happiness, pride, and love (Pangallo et al., 2015). Having supportive relationships was also a common theme characterized by genuine caring and concern (Pangallo et al., 2015). Hardiness was discussed as having characteristics or resourcefulness, a 
sense of commitment, a sense of control over one's life, and an invitation for challenges (Pangallo et al., 2015). The last theme identified was having a structured environment.

The three-factor model of resiliency is associated with the common themes identified in measures of trait resilience (Prince-Embury, 2006). This model is based on Masten's (2001) conceptualization of resilience as developing out of ordinary adaptational systems. The three factors are a sense of mastery, a sense of relatedness, and emotional reactivity. A sense of mastery and relatedness are protective factors that foster resilience, whereas emotional reactivity is a risk factor that impacts resilience. A sense of mastery is conceptualized as mastery motivation described earlier - an individual's competence or efficacy that provides opportunity to interact with the environment and enjoy cause and effect relationships (Prince-Embury et al., 2017; White, 1959). To summarize, the three-factor model conceptualizes a sense of mastery as having optimism or a positive view of the future and oneself, self-efficacy or the belief that one can master their environment, and adaptability or the ability to adjust and change one's behaviour when necessary (Prince-Embury et al., 2017).

A sense of relatedness has been fundamentally a part of resilience in the last five decades (Luthar, 2006). The three-factor model conceptualizes a sense of relatedness as having trust in others, perceived access to support, and comfort with and tolerance of others (Prince-Embury et al., 2017). The importance of relationships has been noted in reviews of protective factors for resilience, hence, a sense of relatedness represents the second protective factor of personal resiliency (Masten \& Obradovic, 2008).

Developmental research has demonstrated that maladjustment and the development of psychopathology in the presence of adversity are related to emotional reactivity (Prince-Embury et al., 2017). Emotional reactivity is the degree to which one responds with a negative emotion 
and how strongly an individual experiences this negative emotion in response to an adverse event (Rothbart \& Derryberry, 1981). In the three-factor model, emotional reactivity is both the negative emotional reaction and one's ability to regulate this emotional reaction (Prince-Embury et al., 2017). This consists of sensitivity, length of recovery time, and degree of disrupted functioning related to the emotional event (Prince-Embury et al., 2017). Emotional reactivity makes the vulnerability factor within this three-factor model.

The three-factor model of resilience is particularly compelling because of how it simplifies the complex construct of resilience concisely and remains comprehensive as it includes eight of the nine common themes of resilience: mastery, self-efficacy, adaptability, active coping, positive affect, supportive relationships, and the importance of a structured environment. It reduces these constructs into lower-level constructs that make up resilience. The three-factor model is also associated with other instruments that measure resilience, such as the Resilience Scale for Children and Adolescents (RSCA; Prince-Embury 2006) and the Resiliency Scale for Young Adults (RSYA; Prince-Embury et al., 2017). Other measures of resilience are often narrowly focused on one or a few components of resilience, lacking the comprehensiveness of the RSCA or RSYA (Prince-Embury et al., 2017). Additionally, other measures frequently possess an inconsistent factor structure that describes resiliency (Prince-Embury et al., 2017). On the other hand, both the RSCA and RSYA measures have a reliable factor structure, validity, and a broad scope of constructs associated with resilience. Since the three-factor model is comprehensive, has an excellent operationalization of resilience as a construct by the measures associated with it, and easy to interpret, this study uses the three-factor model of personal resilience. 
In summary, the specific model used for resilience is the three-factor model of personal resilience (Prince-Embury, 2006). This model is based on Masten's (2015) conceptualization of resilience as developing out of ordinary adaptational systems including a sense of mastery, a sense of relatedness, and emotional reactivity. A sense of mastery and a sense of relatedness are protective factors that foster resilience, whereas emotional reactivity is a risk factor that decreases the likelihood of resilience. For post-secondary students, a sense of mastery is associated with the intention to persist past the first year of post-secondary education (Baier et al., 2016), as well as an increased sense of happiness (Abdel-Khalek \& Lester, 2017). Additionally, post-secondary students report positive mentoring relationships as key to persistence in their post-secondary education (Brroms \& Davis, 2017). Thus, the three-factor model of resilience may predict flourishing, as previous research has consistently shown that resilience is an important source of well-being (Liu et al., 2012).

\section{Present Study}

Both mindful self-care and resilience are important factors in psychological well-being. Research has reliably shown that resilience is an important source of subjective well-being and is positively correlated with life satisfaction and affect (Liu et al., 2012). Studies have shown that resilient individuals could maintain their physical and psychological health through buffering negative consequences from difficult times (Connor \& Davidson, 2003). Resilience may promote the awareness and acceptance aspects of mindfulness because it helps individuals cope with adversity and achieve good adjustment (Bajaj \& Panda, 2016). In addition, resilience may be more pronounced in individuals who practice mindful self-care, as they will engage less in rumination and habitual worrying associated with the trying circumstances in post-secondary education (Bajaj \& Panda, 2016). Thus, individuals who are resilient are also likely to be better 
able to practice mindful self-care. In this study, mindful self-care and resilience are hypothesized to predict flourishing. Moreover, resilience may predict flourishing above and beyond mindful self-care. Studies on mindfulness and self-care have shown mixed findings in its relationship with well-being and mental health, in that, most studies finding significance use a clinical sample and studies looking at a typical population find mixed results. Additionally, many present studies of mindful self-care are based on a singular dimensional measure of mindfulness. This study will look at mindful self-care as a multidimensional operationalization in its relationship with flourishing.

The purpose of the present study was to examine the role that mindful self-care plays in flourishing in first-year undergraduate students. Self-care has been shown to reduce stress in post-secondary students enrolled in a medical degree (Ball \& Bax, 2002; Myers et al., 2012). However, there is lack of research into the role that self-care plays in first-year undergraduate students. Due to the increased risk of psychological distress during the transition to postsecondary education, it is crucial to understand the effects of self-care in this group. Additionally, the present study examined the role that resilience plays in first-year undergraduate students' flourishing and investigated if resilience predicts flourishing beyond self-care. Resilience may aid individuals in adapting to stressful life events that may encourage better adjustment in post-secondary education and increase levels of well-being (Allan et al., 2014; Hartley, 2011; Johnson et al., 2014). Understanding these relationships will help predict which students flourish in post-secondary education, and which students struggle, which can provide valuable information for student resources.

\section{Research Questions and Hypothesis}

This thesis is guided by the following research questions: 
1. Does self-care following Cook-Cottone's (2015a) six factors of mindful self-care (physical care, supportive relationships, mindful awareness, self-compassion and purpose, mindful relaxation, and supportive structure) predict psychological flourishing as defined by Diener and colleagues (2010)?

Studies have shown that the components of mindful self-care such as exercise, healthy eating, social support, mindfulness, and self-compassion are related to well-being (Bray \& Born, 2004; Cappuccio et al., 2011; Hodgins \& Knee, 2002; Leary et al., 2011; Wang \& Eccles, 2012). Specifically, each component of mindful self-care has been positively associated with well-being. However, mindful self-care has not been explored in students transitioning to post-secondary education Additionally, few studies have looked at mindful self-care with Cook-Cotton's six factor model. It is hypothesized that higher scores on the mindful self-care scale will predict greater levels of flourishing.

2. Do the three factors of resilience (sense of mastery, sense of belonging, emotional reactivity) as defined by Prince-Embury and colleagues (2017) predict psychological flourishing?

Resilience is a factor that has been associated with psychological adjustment (Khademi \& Aghdam, 2013). There was a positive correlation that was found between resilience and psychological adjustment (Khademi \& Aghdam, 2013). These findings are consistent with Bowlby's (1969) theory regarding the role of resilience as one of the factors influential in the emergence of healthy adjustment. As such, it is hypothesized that higher scores on the protective factors of personal resilience (sense of mastery and sense of belonging) will predict flourishing, whereas higher scores on the vulnerability factor of 
personal resilience (emotional reactivity) will predict lower self-perceived flourishing (i.e., languishing).

3. Does resilience predict flourishing in first-year undergraduate students beyond selfcare?

Research on resilience has consistently found that resilience is related to psychological well-being. In contrast, research on mindful self-care has presented mixed findings where social support and mindful acceptance were negatively associated with perceived stress and physical care and mindful awareness were not significantly associated with perceived stress (Myers et al., 2012). Due to the consistent findings of the association of resilience and well-being, it is hypothesized that resilience will predict flourishing beyond mindful self-care. 


\section{Chapter 3: Method}

In this chapter, I will discuss the methodology I used to investigate my research questions. This chapter includes an overview of the recruitment process, participants, measures used, data collection procedure, and analysis to support the validity of the findings.

\section{Participants and Recruitment}

Overall, a total of 177 first-year undergraduate students participated in the study. Fortyfour were male, 130 were female, two were transgender, and one was non-binary. The mean age of the participants was 18.0 years $(\mathrm{SD}=0.58)$. Inclusion criteria for participation required the participants to be in the first year of their studies at the University of Calgary, be the first-time they attended post-secondary education, and be able to write, read, and speak English fluently. Recruitment was carried out by presenting the research in first-year classrooms during the fall semester (i.e., Anthropology, Biology, Chemistry, Computer Science, Economics, Engineering, Geography, Greek and Roman Studies, Kinesiology, Mathematics, and Philosophy). Course instructors were first sent an email with a request to be able to present and invite their students to participate in the current research. Upon acceptance from the instructor, the researcher then visited the class and presented a brief rationale for and description of the study, followed by an invitation to participate. A PowerPoint slide was presented with the link to the survey along with the researcher's name and contact information for interested participants to copy down.

Additionally, posters advertising the study were distributed around the University of Calgary campus along with the link to the survey. In appreciation of their time, participants were entered into a draw to win one of three \$25 Amazon gift cards. 


\section{Measures}

The Mindful Self-Care Scale- SHORT (MSCS), the Flourishing Scale (FS), and the Resilience Scale for Young Adults (RSYA) were used in the current study. The following section describes the measures and its reliability and validity.

\section{The Mindful Self-Care Scale-SHORT (MSCS)}

Mindful self-care was assessed using the MSCS (Cook-Cottone, 2016). The MSCS is a 33-item scale that measures self-reported frequency of self-care behaviours including physical care, supportive relationships, mindful awareness, self-compassion and purpose, mindful relaxation, and supportive structure on a 5-point Likert scale. Responses to the items are averaged to provide a subscale score, where a higher subscale score indicates more mindfulness or self-care behaviours. The range of averaged scores are between zero (never engaging in mindfulness or self-care behaviours) to five (regularly engaging in mindfulness or self-care behaviour). The clinical and global items of self-care are not included in the survey as those items were similar to the six factors previously mentioned and could not be averaged.

Cook-Cottone (2016) demonstrate the internal consistency, factor structure, and validity of the MSCS. There was acceptable internal consistency for the six factors, with coefficient alpha values between $\alpha=.69$ and $\alpha=.92$ (Cook-Cottone, 2016). Confirmatory analysis indicated that the six-factor model was a good fit (Cook-Cottone, 2016). In terms of validity, the MSCS demonstrated convergent and divergent validity for all six factors. The MSCS was compared with traditional self-care, trait mindfulness, self-compassion, additional measures of embodiment (e.g., the Body Investment Scale; Orbach \& Mikulincer, 1998).

\section{The Flourishing Scale (FS)}


Psychological well-being was assessed using the FS (Diener et al., 2010). The FS is an 8item scale that measures self-reported social-psychological prosperity, which is a broader construct of well-being on a 7-point Likert scale. All items are phrased in a positive direction and can range from eight (strong disagreement with all items) to 56 (strong agreement with all items). Higher scores signified that respondents view themselves in positive terms in important areas of functioning. The items are based on theoretically universal psychological needs that includes social relationships, self-esteem, purpose in life, optimism, engagement with daily activities, happiness, competence, and life satisfaction. It has demonstrated good internal consistency of $\alpha=.87$. The test-retest correlation with a one-month interval between testing was $r=.71$. This scale was also associated with other measures of well-being such as, the Ryff Scales of Psychological Well-Being (2008) and the Basic Need Satisfaction in General scale (Deci \& Ryan, 2000; La Guardia et al., 2000) with correlations ranging from $r=.42$ to $r=.73$.

\section{Resilience Scale for Young Adults (RSYA)}

Resilience was assessed by the RSYA (Prince-Embury et al., 2017; Smith et al., 2014). The RSYA is a 50-item scale that measures trait resilience in young adults. The items assess three dimensions of resilience - a sense of mastery, a sense of relatedness, and emotional reactivity on a 5-point Likert scale. Responses to the items are totaled to provide a subscale score. A sense of mastery is composed of 15 items ranging from a score of 0-60, with a higher score indicating a greater sense of mastery. A sense of relatedness is composed of 20 items ranging from $0-80$, with a higher score indicating a greater sense of relatedness. Lastly emotional reactivity is composed of 15 items ranging from 0-60, with a higher score indicating greater emotional reactivity. 
Prince-Embury and colleagues (2016) demonstrate internal consistency factor structure, and validity of the RSYA. It demonstrated good internal consistency for the three factors, with coefficient alpha values between $\alpha=.89$ and $\alpha=.92$. Confirmatory factor analysis indicated that a three-factor solution was a good fit compared to a one or two factor solution. The RSYA demonstrated good convergent and divergent validity for all three factors. A sense of mastery and a sense of relatedness were positively correlated with psychological flourishing, satisfaction with life, and emotional intelligence, and negatively correlated with anxiety, stress, and depression. Emotional reactivity was positively correlated with anxiety, stress, and depression, and was negatively correlated with psychological flourishing, satisfaction with life, and emotional intelligence (Prince-Embury et al., 2017).

\section{Procedure}

The present study was approved by Conjoint Faculties Research Ethics Board at the University of Calgary. Participants completed the study on Qualtrics, an online website that facilitates experimental paradigms and data collection. Informed consent was obtained on Qualtrics prior to completing the survey. To ensure anonymity, participants data never had identifiers associated with it and the risk of identification of individuals was low. The first question on the survey screened for eligibility, participants answered the question "what year of

study are you currently in", if participants choose $2^{\text {nd }}, 3^{\text {rd }}, 4^{\text {th }}, 5^{\text {th }}$ year, or a graduate student they were informed they did not meet eligibility criteria for the study. Participants completed the following questionnaires: 1) The Mindful Self-Care Scale- SHORT, 2) The Flourishing Scale, and 3) The Resilience Scale for Young Adults. A short thank you message and a separate link to the draw that cannot be traced to their answers was shown at the end of the survey. 


\section{Analyses}

As the purpose of this study was to investigate the collective ability of a first-year undergraduate student's level of self-care and resilience to predict flourishing, as well as explore the contribution of all of the predictors of whether a first-year undergraduate student flourishes; a standard multiple regression analysis was used. Several assumptions regarding the data needed to be confirmed before performing a standard multiple regression. First, the analysis assumes the sample size was sufficient for the results to be able to be generalized to other samples (Pallant, 2013). A power analysis was conducted in order to determine the minimum number of students

needed for this study. In setting the power level to .80 , alpha level to .05 , and the effect size to $f^{2}$ $=.33$, which are the levels of convention for a multiple regression analysis, which uses nine independent variables (e.g., six self-care variables and three resilience variables), G*Power (3.1.9.2) indicates that a minimum sample of 56 individuals is sufficient.

To examine the first and second question, the relationship among self-care and resilience of first-year undergraduate students and determine if these predictor variables combine to predict the criterion variable of flourishing, a multiple regression was conducted. Two standard multiple regression analyses were used to identify predictors of flourishing using the dependent variable and self-care and resilience as the independent variables. The scores for physical care, supportive relationships, mindful awareness, self-compassion, purpose, mindful relaxation, and supportive structure on the MSCS were used as predictor variables and flourishing on the FS was used as the criterion variable in the first analysis. The scores for a sense of mastery, a sense of relatedness, and emotional reactivity were used as predictor variables, and flourishing on the FS was used as the criterion variable in the second analysis. The regression equation produced by multiple regression predicts flourishing from the six mindful self-care factors and three resilience factors. 
To examine the third question, that resilience predicts flourishing in first-year undergraduate students beyond self-care, a hierarchical regression was utilized. This data analysis method was utilized as it was hypothesized that resilience would account for the largest amount of the variation in flourishing in comparison to self-care (Aswini \& Deb, 2017). Secondly, the order of regression was selected based on the existing literature related to these variables. Though self-care variables such as physical care, supportive structure, purpose, mindful awareness, self-compassion, purpose, and mindful relaxation related to flourishing has not been explored, many studies have found exercise, healthy eating, support, mindfulness, and self-compassion to be significantly related to well-being (Bray \& Born, 2004; Dollete et al., 2004; Leary et al., 2007; Schnettler et al., 2013; Wadlinger \& Isaacowitz, 2011), but these variables were not expected to account for as much of the variation in flourishing as resilience would. Studies have shown a strong relationship between resilience and flourishing, particularly in one study, resilience was amongst the best predictor of flourishing in a study that looks at purpose in life, resilience, and grit (Aswini \& Deb, 2017). It was therefore hypothesized that resilience would account for the largest amount of the variation in flourishing. 


\section{Chapter 4: Results}

\section{Date Preparation}

The data were prepared prior to conducting the analyses. Participants with more than $20 \%$ of their data missing were removed from the analysis. One hundred sixty cases were removed from the dataset as over $80 \%$ of the data were missing, leaving 177 cases. Outliers, defined as a score greater than 3.25 standard deviations away from the mean, were winsorized. Winsorization is changing an outlier from its original value to a value equal to 3.25 standard deviations away from the mean. Three outliers with a score greater than 3.25 were windsorized. Multiple imputation was used to fill in missing values for nine cases. Visual inspection of the QQ plots and histograms suggested that all variables were reasonably normally distributed. The skewness value for the variables ranged from -.88 to .35 and the standardized kurtosis values were between -.38 to .74 . As such, no transformations of data were used.

\section{Preliminary Analysis}

According to guidelines indicated by Cicchetti (1994), all measures demonstrated Coefficient's alpha levels indicating internal consistency from good to excellent aside from the mindful relaxation factor (see Table 1).

The MSCS and RSYA were used to measure the predictor variables and the FS was used to measure the criterion variable. A descriptive analysis was conducted for the predictor variables and criterion variable of the study. Descriptive statistics for the scales are presented in Table 2.

The MSCS is indicative of domains of self-care such as nutrition/hydration, exercise, soothing strategies, self-awareness/mindfulness, rest, relationships, physical and medical practices, environmental factors, self-compassion, and spiritual practices. The domains produce 
six factors of mindful self-care and each domain is averaged, with higher scores representing higher levels of the self-care domain. The mean physical care score for this sample was $M=2.74$ $(S D=.68)$. The mean supportive relationships score was $M=3.83(S D=.87)$. The mean mindful awareness score was $M=3.55(S D=.91)$. The mean self-compassion and purpose score was $M$ $=3.23(S D=.86)$. The mean mindful relaxation score was $M=3.03(S D=.77)$. The mean supportive structure score was $M=3.67(S D=.79)$.

Table 1. Internal Consistencies

\begin{tabular}{lc}
\hline Measure & Coefficient Alpha \\
& $(\alpha)$ \\
\hline MSCS Total (33 items) & .91 \\
Physical Care (8 items) & .72 \\
Supportive Relationships (5 items) & .85 \\
Mindful Awareness (4 items) & .86 \\
Self-Compassion \& Purpose (6 items) & .81 \\
Mindful Relaxation (6 items) & .69 \\
Supportive Structure (4 items) & .77 \\
RSYA Total (50 items) & .88 \\
Sense of Mastery (15 items) & .91 \\
Sense of Relatedness (20 items) & .92 \\
Emotional Reactivity (15 items) & .90 \\
FS Total (8 items) & .87 \\
\hline
\end{tabular}

The MSCS is indicative of domains of self-care such as nutrition/hydration, exercise, soothing strategies, self-awareness/mindfulness, rest, relationships, physical and medical practices, environmental factors, self-compassion, and spiritual practices. The domains produce six factors of mindful self-care and each domain is averaged, with higher scores representing higher levels of the self-care domain. The mean physical care score for this sample was $M=2.74$ $(S D=.68)$. The mean supportive relationships score was $M=3.83(S D=.87)$. The mean mindful awareness score was $M=3.55(S D=.91)$. The mean self-compassion and purpose score was $M$ $=3.23(S D=.86)$. The mean mindful relaxation score was $M=3.03(S D=.77)$. The mean supportive structure score was $M=3.67(S D=.79)$. 
The scores on the RSYA reflect three clusters of typical systems that individuals develop over time and highly influence their levels of resiliency. These three factors are sense of mastery, sense of relatedness, and emotional reactivity. The factors are each totaled, with higher scores for sense of mastery and sense of relatedness representing higher levels of the resilience factor and lower scores for emotional reactivity representing higher levels of the resilience factor. The mean sense of mastery score for this sample was $M=40.02(S D=9.43)$. The mean sense of relatedness score was $M=51.59(S D=12.49)$. The mean emotional reactivity score was $M=$ $24.82(S D=10.20)$.

The FS score reflects respondent's self-perceived success in important areas of psychological well-being such as relationships, self-esteem, purpose, and optimism. The scale provides a single score ranging from 8 to 56 , with higher scores reflecting higher levels of flourishing. The mean flourishing score for this sample was $M=44.35(S D=7.28)$.

Table 2. Descriptive Data for the MSCS and RSYA measures

\begin{tabular}{lcccc}
\hline Variable & Mean & Standard Deviation & Skewness & Kurtosis \\
\hline MSCS & & & & \\
1. Physical Care & 2.74 & .68 & .23 & -.20 \\
2. Supportive Relationships & 3.83 & .86 & -.78 & .17 \\
3. Mindful Awareness & 3.55 & .91 & -.32 & -.31 \\
4. Self-Compassion and Purpose & 3.23 & .86 & .07 & -.38 \\
5. Mindful Relaxation & 3.03 & .77 & .21 & -.06 \\
6. Supportive Structure & 3.67 & .79 & -.35 & -.36 \\
RSYA & & & & \\
7. Sense of Mastery & 40.02 & 9.43 & -.26 & -.36 \\
8. Sense of Relatedness & 51.59 & 12.49 & .12 & -.04 \\
9. Emotional Reactivity & 24.82 & 10.20 & .35 & .24 \\
FS & & & & \\
10. Flourishing & 44.35 & 7.28 & -.88 & .74 \\
\hline
\end{tabular}




\section{Statistical Analyses}

A series of zero-ordered correlation coefficients and regression analysis were used to evaluate relationships among the independent and dependent variables. Correlation coefficients calculated using the criterion and predictor variables were examined. The following guidelines for interpreting correlation coefficients were utilized: 0.50 is large, 0.30 is moderate, and 0.10 is small (Cohen, 1988). Positive correlations were found among the self-care variables, sense of mastery, sense of relatedness, and flourishing. Negative correlations were found among emotional reactivity, self-care variables, and flourishing. Results demonstrated a moderate to large, positive correlation between the six mindful self-care variables and flourishing $(r=.34$ to .66). Additionally, sense of mastery and sense of relatedness showed a large, positive correlation with flourishing ( $r=.69$ to .72 ). Finally, emotional reactivity had a small, negative correlation with flourishing as expected $(r=-.25)$. Correlations are reported in Table 3 .

Table 3: Correlation Matrix among Dependent and Independent Variables

\begin{tabular}{|c|c|c|c|c|c|c|c|c|c|c|}
\hline & 1 & 2 & 3 & 4 & 5 & 6 & 7 & 8 & 9 & 10 \\
\hline 1. & -- & $.26^{* *}$ & $.36 * *$ & $.40 * *$ & $.23 * *$ & $.37 * *$ & $.46^{* *}$ & $.28 * *$ & -.06 & $.34 * *$ \\
\hline 2. & -- & -- & $.47 * *$ & $.57 * *$ & $.42^{* *}$ & $.52 * *$ & $.57 * *$ & $.73^{* *}$ & $-.19 *$ & $.66^{* *}$ \\
\hline 3. & -- & -- & -- & $.65 * *$ & $.42 * *$ & $.55 * *$ & $.61 * *$ & $.41^{* *}$ & $-.30 * *$ & $.43 * *$ \\
\hline 4. & -- & -- & -- & -- & $.60 * *$ & $.57 * *$ & $.65 * *$ & $.54 * *$ & -.11 & $.53 * *$ \\
\hline 5. & -- & -- & -- & -- & -- & $.40 * *$ & $.39 * *$ & $.31 * *$ & -.06 & $.29 * *$ \\
\hline 6. & -- & -- & -- & -- & -- & -- & $.60 * *$ & $.47 * *$ & $-.24 * *$ & $.55 * *$ \\
\hline 7. & -- & -- & -- & -- & -- & -- & -- & $.63 * *$ & $-.36 * *$ & $.69 * *$ \\
\hline 8. & -- & -- & -- & -- & -- & -- & -- & -- & $-.25 * *$ & $.72 * *$ \\
\hline 9. & -- & -- & -- & -- & -- & -- & -- & -- & -- & $-.25 * *$ \\
\hline 10. & -- & -- & -- & -- & -- & -- & -- & -- & -- & -- \\
\hline
\end{tabular}

Note. Please refer to Table 1 for corresponding variables

$*$ indicates $p<.05, * *$ indicates $p<.01$

\section{Research Question One}

The first research question investigates whether the six factors of self-care (physical care, supportive relationships, mindful awareness, self-compassion and purpose, mindful relaxation, 
and supportive structure) predict flourishing in first-year undergraduate students. A multiple regression was conducted to examine each factor of the MSCS as predictors of flourishing (see Table 4). Assumptions tests were conducted to assess linearity, normality, homoscedasticity, independence of residuals, and absence of multicollinearity. The Durbin-Watson tests indicated that there were no serial correlations in the residuals. P-P plots of regression standardized residuals indicated that the relationship between the independent variables and the dependent variable were linear. Additionally, visual inspections of the histograms suggested that error distributions were approximately normal, and scatterplots of standardized residuals and standardized predicted values showed constant variation in the residuals. Multicollinearity was assessed using Variance Inflation Factor (VIF) and Tolerance statistics. The variables in the regression fell within the acceptable range for both VIF and tolerance. The results indicated that the model explained $51.70 \%$ of the variance and that the model significantly predicted flourishing, $F(6,170)=30.34, p<.001$. However, supportive relationships $(\beta=.48, p<.001)$ and supportive structure $(\beta=.22, p=.002)$ were the only significant predictors, while physical care, mindful awareness, self-compassion and purpose, and mindful relaxation were not significant predictors of flourishing $(p>.05)$.

Table 4. Mindful Self-Care Predicting Levels of Flourishing

\begin{tabular}{lccccc}
\hline Predictor Variable & $R^{2}$ & $F$ & $\beta$ & $t$ & $p$ \\
\hline Overall Model & .52 & 30.34 & -- & -- & $<.001$ \\
Physical Care & -- & -- & .11 & 1.88 & .062 \\
Supportive Relationships & -- & -- & .48 & 7.00 & $<.001$ \\
Mindful Awareness & -- & -- & -.02 & -.27 & .787 \\
Self-Compassion \& Purpose & -- & -- & .16 & 1.81 & .072 \\
Mindful Relaxation & -- & -- & -.11 & -1.60 & .111 \\
Supportive Structure & -- & -- & .22 & 3.11 & .002 \\
\hline
\end{tabular}




\section{Research Question Two}

The second question investigates whether the three factors of resilience (a sense of mastery, sense of relatedness, and emotional reactivity) predict flourishing in first-year undergraduate students. A multiple regression was conducted to examine each factor of the RSYA as predictors of flourishing (see Table 5). All assumptions of multiple regression were met (linearity, normality, homoscedasticity, independence of residuals, absence of multicollinearity). The results indicated that the model explained $61.40 \%$ of the variance and that the model significantly predicted flourishing, $F(3,172)=91.314, p<.001$. However, sense of mastery $(\beta=.39, p<.001)$ and sense of relationship $(\beta=.48, p<.001)$ were the only significant predictors, while emotional reactivity was not a significant predictor of flourishing $(p>.05)$. Table 5. Resilience Predicting Levels of Flourishing

\begin{tabular}{lccccc}
\hline Predictor Variable & $R^{2}$ & $F$ & $\beta$ & $t$ & $p$ \\
\hline Overall Model & .61 & 91.31 & -- & -- & $<.001$ \\
Sense of Mastery & -- & -- & .39 & 6.17 & $<.001$ \\
Sense of Relatedness & -- & -- & .48 & 7.80 & $<.001$ \\
Emotional Reactivity & -- & -- & .01 & .19 & .848 \\
\hline
\end{tabular}

\section{Research Question Three}

The third question investigates whether resilience predicts flourishing beyond self-care. A two-step hierarchical multiple regression was performed using flourishing as the dependent variable (see Table 6). Mindful self-care factors were the predictor variables entered at the first step and the three resilience factors were entered into the second step of the hierarchical regression model. The sequence of entries was guided by the literature review that resilience would account for more variation in flourishing. As shown in the analysis of research questions 
one and two, the resilience model predicted $61.40 \%$ of the variance, while mindful self-care model predicted $51.70 \%$ of the variance in flourishing.

Mindful self-care was entered into the first block and was found to be a significant predictor, $F(6,169)=30.21, p<.001$, explaining $51.70 \%$ of the variance. When mindful selfcare variables were held constant, the model of resilience predicted flourishing $F(9,166)=$ $33.79, p<.001$, explaining $64.7 \%$ of unique variance in the model. Specifically, supportive relationships $(\beta=.20, p=.008)$, supportive structure $(\beta=.14, p=.036)$, sense of mastery $(\beta=$ $.33, p<.001)$, and sense of relatedness $(\beta=.34, p<.001)$ were significant predictors. Physical care, mindful awareness, self-compassion and purpose, mindful relaxation, and emotional reactivity were not significant predictors of flourishing $(p>.05)$.

Table 6. Regression Analysis for Resilience Predicting Flourishing beyond Mindful Self-Care

\begin{tabular}{llcccc}
\hline Predictor Variable & $R^{2}$ & $F$ & $\beta$ & $t$ & $p$ \\
\hline Step 1 & .52 & 30.21 & -- & -- & $<.001$ \\
Physical Care & -- & -- & .11 & 1.91 & .058 \\
Supportive Relationships & -- & -- & .48 & 6.99 & $<.001$ \\
Mindful Awareness & -- & -- & -.02 & -.28 & .778 \\
Self-Compassion \& Purpose & -- & -- & .16 & 1.81 & .072 \\
Mindful Relaxation & -- & -- & -.11 & -1.62 & .108 \\
Supportive Structure & -- & -- & .22 & 3.07 & .002 \\
Step 2 & .65 & 33.79 & -- & -- & $<.001$ \\
Sense of Mastery & -- & -- & .33 & 4.23 & $<.001$ \\
Sense of Relatedness & -- & -- & .34 & 4.61 & $<.001$ \\
Emotional Reactivity & -- & -- & .00 & .00 & .998 \\
\hline
\end{tabular}




\section{Chapter 5: Discussion}

The primary purpose of the current study was to explore the relationship between mindful self-care, resilience, and flourishing in first-year undergraduate students. Specifically, mindful self-care and resilience were investigated as predictors of flourishing in first-year undergraduate students. Based on previous research, resilience was hypothesized to predict flourishing above and beyond mindful self-care.

\section{Research Question One}

The first question examined whether mindful self-care variables were predictors of flourishing in first-year undergraduate students. The conceptualization of mindful self-care utilized in the current study included six factors: physical care, supportive relationships, mindful awareness, self-compassions \& purpose, mindful relaxation, and supportive structure. Past research exploring these six factors have revealed mixed findings. Myers and colleagues (2012) provided the foundation for the current research on links between self-care practices and healthrelated behaviours. Results revealed that perceived social support and mindful acceptance were negatively associated with perceived stress after controlling for the effects of demographic variables (Myers et al., 2012). However, engagement in exercise, mindful awareness, and frequency of formal mindfulness practices were unrelated to perceived stress in graduate students (Myers et al., 2012). To investigate these relationships further, it was hypothesized that mindful self-care would predict levels of flourishing in transitioning first-year undergraduate students. Specifically, higher scores of the mindful self-care variables would predict higher levels of flourishing in first-year undergraduate students. Results from the current study found that the overall model of self-care predicting flourishing was significant. Further analysis at the factor level revealed that supportive relationships and supportive structure were significant predictors 
of flourishing. However, physical care, mindful awareness, self-compassion \& purpose, and mindful relaxation did not significantly predict flourishing. These findings are consistent with studies that have found relationships between psychological adjustment and well-being of social support and non-significant effects associated with mindfulness practices and physical activity (Moses et al., 2016; Myers et al., 2012).

The supportive relationships factor of mindful self-care emphasizes spending time with people who support, encourage, and believe in the individual and feeling supported. It is predicted that those with higher perceived social support would report higher levels of flourishing. Although there is limited research looking at supportive relationships and flourishing, it is widely accepted that social support influences health and well-being (Liu et al., 2016). Social isolation, missing home, and struggling to forge new friendships are connected to languishing, while a supportive social system has helped participants thrive (Knoesen \& Naudé, 2018). Integration into a university's social community may be crucial in developing a sense of belonging, as students are building new friendships and some are living as independent adults (Parker et al., 2005). In addition, having supportive relationships during the first year of postsecondary education may contribute to increased positive emotions by providing opportunity to relax and have fun with friends. Further, having supportive friendships may encourage students to engage in increased learning behaviours, such as participating in study groups that fulfills personal growth and satisfy a sense of belonging (i.e., social acceptance). Indeed, all of these positive aspects of supportive relationships are a part of flourishing.

The supportive structure factor in mindful self-care relates to keeping a manageable and organized schedule (Cook-Cottone, 2016). It also relates to maintaining a comforting and pleasing living environment (Cook-Cottone, 2016). Those with higher levels of supportive 
structure are predicted to report higher levels of flourishing. Few studies have examined supportive structure as related to maintaining organization and a manageable schedule and living environment. However, occupational health research found that work organization and health are inextricably linked (Levecque et al., 2017). A manageable and organized schedule encompasses strategies to maintain balance between work and home. Research has demonstrated that worklife interference is high when students need to study on evenings and weekends (El-Ghoroury et al., 2012). Work-life conflict has been linked to psychological distress (Kinman et al., 2006; Levecque et al., 2017). Higher levels of supportive structure may allow individuals to flourish more because a sense of life harmony and optimal psychophysiological conditions can help them meet the long-term demands of post-secondary studies (Greenhaus et al., 2003). Keeping a manageable and organized schedule may lessen student apprehensiveness about their abilities to balance commitments within and outside of school. This may lead to a reduction in negative thoughts about life imbalance, which deplete physical and mental resources (Rothbard, 2001). With the benefits of having a supportive structure, it is no surprise that it predicts flourishing in undergraduate students.

On the mindful self-care scale, the physical care factor entails engaging in exercise and healthy eating (Cook-Cottone, 2016). It was hypothesized that higher levels of physical care would predict higher levels of flourishing. One of the possibilities for the lack of significant findings is that participants completed the survey around midterm exams in the fall and may be less likely to engage in physical care during this time. Additionally, healthy eating might require higher levels of self-awareness in order to be associated with student's ability to flourish. Gilbert and Waltz (2010) noted that greater self-awareness assists individuals in the monitoring and regulation of food intake. In this case, careful observation of thoughts and feelings associated 
with eating may increase a person's capacity to refrain from distress eating that is linked to negative emotional reactions (Gilbert \& Waltz, 2010). Studies have shown that post-secondary students tend to gain more weight than those who do not attend university because of time constraints, high price of food items, and lack of motivation in food preparation (Sogari et al., 2018). If first-year undergraduate students obtain training in mindful eating, it may help increase their self-awareness of foods that make them energetic and feel good in order to increase chances of flourishing.

The mindful awareness factor in mindful self-care relates to calm awareness of one's thoughts, feelings, and body (Cook-Cottone, 2016). It was hypothesized that higher levels of mindful awareness would predict higher levels of flourishing. A possible explanation for the insignificant results is that the perception of what it means to engage in calm awareness of one's thoughts, feelings, and body may vary between participants, as the study on mindfulness has grown rapidly over the past few years. In addition, having a calm awareness of one's thoughts, feelings, and body does not necessarily mean that individuals are actively engaging in strategies to mitigate negative thoughts, feelings and physiological patterns, thus, there may be another step in the process before mindful awareness predicts flourishing. It is possible that the inherent limitations of assessing mindful awareness influenced the results of this study. However, there is no clear empirical evidence suggesting that self-report measurement methods of mindful awareness significantly influenced the relationship between mindful awareness and flourishing.

The self-compassion and purpose factor relates to acknowledging challenges and difficulties as well as engaging in supportive and comforting self-talk. Further, it relates to experiencing a larger purpose in life. Those with higher levels of self-compassion and purpose are predicted to have higher levels of flourishing. Results of testing showed no significant 
prediction, which may be attributed to the majority of the sample size being female. Research has shown that self-compassion tends to be slightly (but significantly) lower among women than men (Neff et al., 2007). Past research has shown that women are often more self-critical and ruminate on negative aspects of themselves more than men (Leadbeater et al., 1999). Future research should explore gender differences in terms of self-compassion and flourishing. The link between self-compassion and flourishing may also be attributable to age. Studies have shown that people become more self-compassionate later in life, especially when they reach the stage of integrity at age 65 proposed by Erikson (1963), which involves acceptance of the self (Neff, 2011). However, self-compassion is a skill that can be taught to post-secondary students and may in turn promote flourishing.

On the mindful self-care scale, the mindful relaxation factor relates to engaging in intellectual, interpersonal, or creative activities to relax (Cook-Cottone, 2015). It also entails seeking out images or smells (e.g., art and/or candles) that induce relaxation. It was hypothesized that higher levels of mindful relaxation would predict higher levels of flourishing. A possible explanation for the statistically nonsignificant results is that mind-body activities such as mindful relaxation may require more efforts than the more tangible external activities (i.e., seeking supportive relationships and supportive structure; Hotchkiss \& Lescher, 2018). For example, Baer (2015) suggested that awareness of a particular domain (e.g., interpersonal domain) can be more salient than that of other domains (e.g., creative domain). Accessing the creative domain may require more effort, making it more elusive, lowering the mindful relaxation factor score. In addition, the scale gauges for frequency of behaviours within the past week, allowing for student time constraints that may preclude engaging in mindful relaxation activities (Huberty et al., 2019). Other measures such as the Mindful Attention Awareness Scale (MAAS; Brown \& Ryan, 
2003) and the Five Facet Mindfulness Questionnaire (FFMQ; Baer et al., 2006) does not ask for participants to gauge frequency within the past week, which broadens the time constraint and may allow for a more accurate frequency of mindful relaxation in a semester to predict flourishing.

\section{Research Question Two}

The second research question sought to examine whether resilience variables were predictors of flourishing in first-year undergraduate students. Past research exploring resilience as predictors of well-being and positive mental health have revealed mixed findings. While most studies have found that resilience has been associated with life satisfaction, positive mental health, and greater well-being (Hartley, 2011; Stack-Cutler et al., 2014), others have found that certain factors of resilience (e.g., a sense of mastery) predicts flourishing in an academic setting better than other factors (e.g., emotional reactivity; Wilson et al., 2019). To investigate these relationships further, it was hypothesized that resilience variables from the RSYA would predict levels of flourishing in first-year undergraduate students. Specifically, higher scores on the sense of mastery and sense of relationship factor and lower scores on the emotional reactivity factor would predict flourishing in students. Results from the current study found that the overall model of resilience predicting flourishing was significant. Further analysis at the factor level revealed that sense of mastery and sense of relatedness were significant predictors of flourishing in firstyear students. However, emotional reactivity was not found to be predictive of flourishing. These findings are consistent with studies that show students who evinced protective factors (e.g., relatedness, autonomy, and competence) predicted changes in academic achievement and increased psychological well-being (Pitzer \& Skinner, 2017). Emotional reactivity and success in college-aged students requires further exploration as the academic implications of poor 
emotional regulation and negative emotionality have primarily been studied in young students Wilson et al., 2019).

The sense of mastery factor in the three factors of resilience emphasizes optimism, selfefficacy, and adaptability (Prince-Embury et al., 2017). It was predicted that those with a higher perceived sense of mastery would report higher levels of flourishing. Although there is limited research looking at one's sense of mastery and flourishing, it is widely accepted that competence and self-efficacy influence health and well-being (White, 1959). Self-determination theory posits that humans have three basic needs including autonomy and competence (components of mastery) that may function as a motivational resource that drives engagement and achievement (Ryan \& Deci, 2001). Driven by an innate curiosity that is intrinsically rewarding and is a source of problem-solving skills, a sense of mastery is a key protective factor for successful completion of university (Saklofske et al., 2013). Having a sense of mastery may create a strong sense of autonomy and self-determination that contributes a positive cognitive-motivational state involved in the realization of clear and definite personal vital goals necessary for post-secondary education (Garcia-Alandete, 2015). In addition, flourishing is not only about experiencing positive affect, but is rather perceiving that life is valuable, setting goals, and striving to reach them. Thus, it is no surprise that a sense of mastery predicts flourishing (Garcia-Alandete, 2015). The sense of relatedness factor in the three factors of resilience relates to trust, perceived access to support, comfort with others, and tolerance of others (Prince-Embury et al., 2017). It was hypothesized that those with higher sense of relatedness scores would report higher levels of flourishing. Researchers have posited that the need for relatedness is a universal human need (Baumeister \& Leary, 1995). When the need for belongingness is fulfilled, people experience higher levels of well-being and overall functioning (Ryan \& Deci, 2001). Studies in 
biopsychology have also found a link between biological correlates of relatedness and outcomes of well-being (Bartz et al., 2014). Leighton and colleagues (2016) proposed that a trusting relationship is critical in the learning process, as such a sense of relatedness may predict flourishing as it leads students to experience the ability to tackle challenges and express new ideas in a trusting, supporting relationship. It is important for students to be able to make mistakes in the process of acquiring newly learned knowledge and skills and develop confidence to accept feedback. Indeed, it is often reported that schools have made significant learning gains when mutual well-being is addressed, based on positive and trusting relationships within a learning community (Sebring \& Bryk, 2000). Thus, the present findings support existing research on the association between a sense of relatedness and flourishing.

On the three-factor resilience scale, the emotional reactivity factor relates to length of recovery time from an emotional upset, impairment or degree of disrupted functioning, and sensitivity (Prince-Embury et al., 2017). It was hypothesized that lower levels of emotional reactivity would predict higher levels of flourishing, as emotional reactivity is a vulnerability factor. A possible explanation for the statistically nonsignificant results is that due to the timing of data collection during October, students may not have had a time of emotional upset (e.g., midterms, final exams, and projects) during their semester that they could recall. In addition, first-year undergrads are typically more involved in clubs and activities during their first few months and may be still experiencing the euphoria of meeting new classmates (Foubert \& Grainger, 2006). Therefore, the lack of academic pressure and positive involvement in campus life may buffer emotional reactivity and thus, does not predict flourishing at this time. 


\section{Research Question Three}

The third research question explored whether the three factors of resilience variables predicted flourishing after controlling for self-care variables. The overall model of resilience accounted for an additional $13 \%$ of the variation in flourishing scores above and beyond that accounted for by the self-care variables. Specifically, a sense of mastery and a sense of relatedness were significantly positive. This means that greater sense of mastery and sense of relatedness increases flourishing. Past research has shown that a sense of mastery is related to life satisfaction and a sense of purpose that is important in flourishing (Garcia-Alandete, 2015). Similarly, a sense of relatedness is related to trying new things and taking risks related to flourishing (Leighton et al., 2016). In addition, according to the regression results, the self-care variables of supportive relationships and supportive structure were significantly positive. This indicates that the more perceived supportive relationships and supportive structure (keeping a manageable and organized schedule and environment), the higher the flourishing scores. This study supported the literature that examined the importance of social support and optimal psychophysiological conditions on well-being (Greenhaus et al., 2003; Knoesen \& Naudé, 2018).

Overall, both self-care variables and resilience variables contributed significantly to some of the unique variation in flourishing. The hierarchical regression model was chosen for this study because it was expected that both self-care and resilience would contribute to the variation in flourishing scores, but that resilience factors would contribute the most to the variation in flourishing scores. Research has consistently shown that resilience is an important source of subjective well-being and is positively correlated with life satisfaction and positive affect (Liu et al., 2012). Resilience should be more pronounced in individuals who practice mindful self-care, as they will engage less in rumination and habitual worrying associated with trying 
circumstances in post-secondary education (Bajaj \& Panda, 2016). Resilient individuals are better able to respond to difficult situations without reacting in automatic and non-adaptive ways (Bajaj \& Panda, 2016). Studies have shown that resilient individuals could maintain both their physical and psychological health through buffering negative consequences from difficult times (Connor \& Davidson, 2003). Many present studies of mindful self-care are based on a singular dimensional measure of mindfulness. However, mindful self-care is a multidimensional operationalization (Cook-Cottone, 2015) and supportive relationships and supportive structure are just a few of the many multiple facets that may enhance flourishing.

\section{Strengths of the Current Study}

The current study was one of the first of its kind. While previous studies have focused on a clinical population and medical students, the current study examined mindful self-care and resilience in first-year undergraduate students. This allowed for the examination of mindful selfcare and resilience during the transition period between high school and university.

The variables in this study are well-established in different populations and this is what made it possible to do regression analyses because of the theoretical background. Additionally, with the chosen methodology, the model reflects theory about the relations among both mindful self-care and resilience with flourishing.

The sample used in the current study is large which allows for statistical power. While many studies often lack variety in their participant pool, the current study's sample was more diverse in gender and race allowing for more generalizability than previous studies.

\section{Implications}

Results from the present study have several implications for both research and practice. Research has suggested that resilience and mindful self-care can be improved through resilience 
building and mindfulness-based programs (Crowder \& Sears, 2017). Studies indicate that $50 \%$ to $80 \%$ of college students who struggle with mental health do not seek treatment (Oswalt et al., 2020). The current study revealed that supportive relationships, supportive structure, a sense of mastery, and a sense of relatedness are important predictors of flourishing. Thus, institutions may target social support and skill acquisition associated with supportive structure and a sense of relatedness through group interventions. Research has shown that individuals are more likely to attend a universal program rather than seek professional mental health services due to cost, stigma, and recognition of symptoms such as in the case of languishing (Gulliver et al., 2010). Akeman and colleagues (2020) implemented a universal resilience program for first-year college students and found that the intervention had a positive impact on perceived stress, mindfulness, and emotional regulation skills compared with students who did not receive training. Thus, the importance of resilience and mindful self-care in flourishing is clear and the effectiveness of universal resilience programs should be considered in all institutions.

Research has demonstrated that there are many aspects of resilience that are teachable (Reivich et al., 2011; Seligman et al., 2009). These aspects include optimism, problem solving, self-efficacy, flexibility, and impulse control (Masten \& Reed, 2002). The Penn Resilience Program (PRP) focuses on these factors identified by Masten and Reed (2002) for students in late childhood and early adolescence. A parallel program that focused on preventing depression and anxiety in college students called APEX also found positive outcomes (Gillham et al., 1991). Both programs improved social skills which is important regarding the study's finding of various predictive factors on flourishing. This includes supportive relationships and a sense of relatedness. Additionally, the program improved cognitive skills such as optimism, effective problem solving, and self-efficacy (i.e., sense of mastery; Reivich et al., 2011) on flourishing. 
This shows that resilience programs are beneficial for early adolescence and university students in preventing mental health issues and promoting flourishing.

Post-secondary institutions may want to mobilize the information gathered through this research and apply it to interventions and institutional programming. The possible benefits of doing so may lead to flourishing and help maximize the success rate of first year undergraduates. The research can be used in developing group workshops, to be delivered beginning in orientation week and throughout the first semester into exams. The purpose of these workshops would be to heighten self-awareness and benefits of self-care and to build positive coping behaviours and resiliency. Additionally, supportive relationships and a sense of relatedness were factors that strongly predicted flourishing in this study. Ehrich and colleagues (2002) identified six most frequently cited positive outcomes for mentees: support, encouragement, friendship, help with learning strategies, increased confidence, advice from peers, and career affirmation. Therefore, the concept of pairing first-year students with a mentor may provide them with a further support system during the stressful transition from high school to university, which can eventually help them flourish and thrive throughout the years.

Given the importance of resilience in flourishing, school psychologists may want to include a resilience scale in their assessments, particularly for students transitioning to postsecondary education. In addition, school psychologists should include self-care strategies in their recommendations due to their benefits. Research has long shown that resilience factors, both external and internal, influence positive youth development and protect adolescents from engagement in health risk behaviours (Benard, 1991; Glantz \& Johnson, 1999). Health risk behaviour prevention programs have fostered a resilience-based approach and assessing student's resilience may help place students in these types of programs (Constantine et al., 1999). The 
school can provide these developmental supports and opportunities that promote positive developmental outcomes in youth (resilience traits), resulting in improved health, social, and academic outcomes (Constantine et al., 1999). These resilience-based programs have created a demand for a comprehensive assessment of resilience factors in children and youth.

\section{Limitations}

There are several limitations in this study that are acknowledged and results should be considered within the context of these limitations. These relate to the sample of participants, the measurement of variables, and the collection of data.

\section{Sample Limitations}

There was a potential selection bias in the sample of participants. As the study took approximately an hour to complete and was completely voluntary, the sample may not be representative of the population of students experiencing the transition to post-secondary studies. Research has shown that individuals with lower levels of adjustment were less likely to volunteer for studies that involved revealing one's inner self (Lönnqvist et al., 2007). Given that self-care, resilience, and flourishing can be sensitive topics revealing one's inner self, there is a possibility that students who are struggling or less engaged academically may be less likely to volunteer their time to complete a study. As such, the results may not be valid for students who are unmotivated or struggling with their studies. To combat the potential selection bias, the researcher recruited from a variety of first-year undergraduate courses. Further, there was a gender imbalance in the sample with the participants consisting predominantly of females (73\%). This limitation should be considered when interpreting the results.

The lack of diversity in the sample may have limited the findings of this study, as the sample may not be representative of the general population, but rather a specific subgroup with 
unique motivation. Although a focus of our current research is on postsecondary student success, it is also limited by using a sample of undergraduate students. Education is a proxy of socioeconomic status (SES) and both education and SES are protective factors that influence resilience and flourishing (Clauss-Ehlers, 2008). Due to the lack of diversity in the sample, this may have limited the findings, as the sample may be representative of a specific subgroup in the population. An added variable such as SES may be beneficial to control for this limitation.

\section{Measurement Limitations}

Since the study was unfunded, only scales that were freely accessible were used. Additionally, due to the uncontrolled nature of an online study, only unprotected measures could be used to avoid unintentionally releasing a secure instrument to the public. These two limitations prevented the selection of some other high-quality or commonly used measures of resilience or mindful self-care. The resilience and mindful self-care scales that was used in this study were multidimensional construct measures and thus a total score could not be derived. One of the greatest difficulties for measuring resilience has been that resilience is not a single ability construct (Prince-Embury et al., 2017). People are resilient to different degrees depending on the situation and context, and people may rely on many different coping abilities. The RSYA does not purport to assess all aspects of personal resiliency in all situations (Prince-Embury et al., 2017). However, future researchers may want to look at resilience and mindful self-care over the first year of undergraduate studies to determine the varying degree of each construct during the transition from high school to university.

All scales used in this study are self-report scales and share the limitations of other assessments using this type of measurement format. Response bias, that ranges from misunderstanding of what the measure is asking to social-desirability bias, occurs when 
individuals offer self-assessed measures of some phenomenon (Rosenman et al., 2011). Some measures of resilience and self-care include a positive impression scale or checks for response style. However, the RSYA and MSCS do not include such checks, which may limit findings of the current study. To combat this limitation, the responses were kept anonymous to minimize social-desirability bias.

\section{Assessment of Mindful Self-Care}

The MSCS is the first measure to assess constructs of mindfulness and self-care (CookCottone, 2016). The measure only looks at frequency of behaviour within the past seven days. This can be problematic because participants can vary in the amount of mindful self-care during the semester. For example, when students are stressed during exam times, they are less likely to eat healthy, exercise, and engage in relaxing activities (Huberty et al., 2019; Sogari et al., 2018). Silliman and colleagues (2004) found that $84 \%$ of college students stated they currently exercise, however, $42 \%$ of those students stated they have exercised less since attending college. Dietary habits are established in early life and healthy eating is more common in students living at home (Silliman et al., 2004). Future researchers may want to expand the timeframe for reporting on or considering the frequency for behaviour to get a general picture of the daily process of mindful self-care.

\section{Future Directions}

Future researchers may consider replicating the results using different instrumentation and populations, as well as repeating this study using different outcome variables. It is possible that resilience and mindful self-care have different degrees of predictive validity for different populations. Comparing the predictive validity of measures of resilience and mindful self-care will provide greater insight into the validity and generalizability of the study's findings. In 
addition, outcome variables could include common challenges in post-secondary education such as dropout, problematic substance use, or psychopathology. This will provide a lens into specific risks faced by first-year undergraduate students.

Given the cross-sectional nature of the present study, the results of this study provide information for a single point in time. Looking at the roles that resilience and self-care play in flourishing over a longer period of time could provide valuable information. For example, it would be beneficial to look at whether resilience and self-care predicts flourishing prior to attending higher education or if these predictors become more relevant during post-secondary studies. The longitudinal methodology could be combined with mediating variables as well, such as SES, gender, program of study, and living arrangement.

A path analysis could extend this research to better capture the complexity of the transition to post-secondary studies or to further make predictions about the effects of mindful self-care and resilience on flourishing. Several final dependent variables of interest that relate to student success such as mindful self-care and resilience factors could be explored. This would provide graphical representations of a set of relationships among mindful self-care, resilience, and flourishing that concisely and visually summarize those relationships. Further, a path analysis produces a correlation matrix that plays an important role in assessing the validity of a given causal model.

\section{Conclusion}

The study draws attention to the importance of studying mindful self-care and resilience during more ordinary stressors, such as the transition to higher education. Understanding the roles that mindful self-care and resilience play may allow for an increase in flourishing and improvement of personal and academic growth for a large portion of the young adult population. 
Students with higher levels of mindful self-care in the area of supportive relationships and supportive structure were flourishing. In addition, students with higher levels of resilience in the factors of sense of mastery and sense of relatedness also were flourishing. This may allow postsecondary institutions to improve students' mental health, academic performance, and retention rates by understanding the relationships between resilience, mindful self-care and flourishing. Although more research is required to realize these potential benefits due to the limitations of this study, these results provide an important early step in understanding how mindful self-care and resilience contribute to flourishing in first-year undergraduate students. Supporting students during this time can vastly enrich their lives through the foundation for their careers and relationships. 


\section{References}

Abdel-Khalek, A. M., \& Lester, D. (2017). The association between religiosity, generalized selfefficacy, mental health, and happiness in Arab college students. Personality and Individual Differences, 109, 12-16. https://doi.org/10.1016/j.paid.2016.12.010

Aburn, G., Gott, M., \& Hoare, K. (2016). What is resilience? An integrative review of the empirical literature. Journal of Advanced Nursing, 72(5), 980-1000. https://doi.org/10.1111/jan.12888

Agaibi, C. E., \& Wilson, J. P. (2005). Trauma, PTSD, and resilience: A review of the literature. Trauma, Violence, \& Abuse, 6(3), 195-216. https://doi.org/10.1177/1524838005277438

Akeman, Elisabeth, Kirlic, Namik, Clausen, Ashley N, Cosgrove, Kelly T, McDermott, Timothy J, Cromer, Lisa D, Paulus, Martin P, Yeh, Hung-Wen, \& Aupperle, Robin L. (2019). A pragmatic clinical trial examining the impact of a resilience program on college student mental health. Depression and Anxiety, 37(3), 202-213. https://doi.org/10.1002/da.22969

Allan, John F, McKenna, Jim, \& Dominey, Susan. (2014). Degrees of resilience: profiling psychological resilience and prospective academic achievement in university inductees. British Journal of Guidance \& Counselling, 42(1), 9-25. https://doi.org/10.1080/03069885.2013.793784

Anthony, E. J. (1974). The syndrome of the psychologically invulnerable child. In E. J. Anthony \& C. Koupernik (Eds.), The child in his family: Children at psychiatric risk (pp. 529545). New York: Wiley.

Aswini, S., \& Deb, A. (2017). Flourishing among postgraduate students: the role of resilience, meaningfulness and grit. Indian Journal of Community Psychology, 13(1), 24. 
https://ink.gale.com/apps/doc/A488193682/EAIM?u=ucalgary\&sid=EAIM\&xid=1bf8d3 $\underline{34}$

Baer, Ruth A, Smith, Gregory T, Hopkins, Jaclyn, Krietemeyer, Jennifer, \& Toney, Leslie. (2016). Using Self-Report Assessment Methods to Explore Facets of Mindfulness. Assessment (Odessa, Fla.), 13(1), 27-45. https://doi.org/10.1177/1073191105283504

Bajaj, Badri, \& Pande, Neerja. (2016). Mediating role of resilience in the impact of mindfulness on life satisfaction and affect as indices of subjective well-being. Personality and Individual Differences, 93, 63-67. https://doi.org/10.1016/j.paid.2015.09.005

Baier, Stefanie T, Markman, Barry S, \& Pernice-Duca, Francesca M. (2016). Intent to Persist in College Freshmen: The Role of Self-Efficacy and Mentorship. Journal of College Student Development, 57(5), 614-619. https://doi.org/10.1353/csd.2016.0056

Ball, S., \& Bax, A. (2002). Self-care in medical education: effectiveness of health-habits interventions for first-year medical students. Academic Medicine, 77(9), 911-917. https://journals.lww.com/academicmedicine/Fulltext/2002/09000/Self_care_in_Medical Education Effectiveness of.23.aspx.?casa token=Rm6Cq4z0NaAAAAAA:NUzW9nIt Kzu10BzO5m6dYrEEpbki65c8K8wDBtQdwJGgfnuyusfoUph3xL8XJRdKLz4hGEDtx8 2cCNrfQL5pmmZyxP13

Bandura, A. (1977). Self-efficacy: Toward a unifying theory of behavioral change. Psychological Review, 84(2), 191-215. https://doi.org/10.1037//0033295X.84.2.191

Barker, E. T., \& Galambos, N. L. (2007). Body dissatisfaction, living away from parents, and poor social adjustment predict binge eating symptoms in young women making the 
transition to university. Journal of Youth and Adolescence, 36(7), 904-911. https://doi.org/10.1007/s10964-006-9134-6

Bartz, J. A., Zaki, J., Bolger, N., \& Ochsner, K. N. (2011). Social effects of oxytocin in humans: context and person matter. Trends in cognitive sciences, 15(7), 301-309. https://doi.org/10.1016/j.tics.2011.05.002

Baumeister, R. F., \& Leary, M. R. (1995). The need to belong: desire for interpersonal attachments as a fundamental human motivation. Psychological bulletin, 117(3), 497. https://doi.org/10.1037/0033-2909.117.3.497

Benson, H. (1993). The relaxation response. In Goleman, D., \& Gurin, J. (Eds.), Mind body medicine: How to use your mind for better health (pp. 233-257). New York, NY: Consumers Reports Book.

Bjelland, I., Dahl, A. A., Haug, T. T., \& Neckelmann, D. (2002). The validity of the Hospital Anxiety and Depression Scale: an updated literature review. Journal of psychosomatic research, 52(2), 69-77. https://doi.org/10.1016/S0022-3999(01)00296-3

Block, J., \& Kremen, A. M. (1996). IQ and ego-resiliency: conceptual and empirical connections and separateness. Journal of personality and social psychology, 70(2), 349. https://doi.org/10.1037/0022-3514.70.2.349

Bradburn, N. M., \& Noll, C. E. (n.d.). The structure of psychological well-being.

Brooms, D. R., \& Davis, A. R. (2017). Staying focused on the goal: Peer bonding and faculty mentors supporting Black males' persistence in college. Journal of Black Studies, 48(3), 305-326. https://doi.org/10.1177/0021934717692520 
Brown, K. W., \& Ryan, R. M. (2003). The benefits of being present: mindfulness and its role in psychological well-being. Journal of personality and social psychology, 84(4), 822. https://doi.org/10.1037/0022-3514.84.4.822

Burns, R. A., \& Anstey, K. J. (2010). The Connor-Davidson Resilience Scale (CD-RISC): Testing the invariance of a unidimensional resilience measure that is independent of positive and negative affect. Personality and Individual Differences, 48(5), 527-531. https://doi.org/ 10.1016/j.paid.2009.11.026

Cappuccio, F. P., Cooper, D., D'Elia, L., Strazzullo, P., \& Miller, M. A. (2011). Sleep duration predicts cardiovascular outcomes: a systematic review and meta-analysis of prospective studies. European heart journal, 32(12), 1484-1492. https://doi.org/10.1093/eurheartj/ehr007

Carroll, L., Gilroy, P. J., \& Murra, J. (1999). The moral imperative: Self-care for women psychotherapists. Women \& Therapy, 22, 133-143. https://doi.org/10.1300/J015v22n02_10

Casella, L., \& Motta, R. W. (1990). Comparison of characteristics of Vietnam veterans with and without posttraumatic stress disorder. Psychological Reports, 67(2), 595-605. https://doi.org/10.2466/pr0.1990.67.2.595

Clark, L. A., \& Watson, D. (1991). Tripartite model of anxiety and depression: psychometric evidence and taxonomic implications. Journal of abnormal psychology, 100(3), 316. https://doi.org/10.1037//0021-843X.100.3.316

Clauss-Ehlers, C. S. (2008). Sociocultural factors, resilience, and coping: Support for a culturally sensitive measure of resilience. Journal of Applied Developmental Psychology, 29(3), 197-212. https://doi.org/10.1016/j.appdev.2008.02.004 
Connor, K. M., \& Davidson, J. R. (2003). Development of a new resilience scale: The ConnorDavidson resilience scale (CD-RISC). Depression and anxiety, 18(2), 76-82. https://doi.org/10.1002/da.10113

Constantine, N., Benard, B., \& Diaz, M. (1999, June). Measuring protective factors and resilience traits in youth: The healthy kids resilience assessment. In seventh annual meeting of the Society for Prevention Research, New Orleans, LA (pp. 3-15).

Cook-Cottone, C. P. (2015). Mindfulness and yoga for self-regulation: A primer for mental health professionals. Springer Publishing Company.

Cook-Cottone, C. P., \& Guyker, W. (2017). The mindful self-care scale: Mindful self-care as a tool to promote physical, emotional and cognitive well-being. Mindful Therapy, 1, $x-x x$. https://doi. org/10.1037/t66058-000

Crowder, R., \& Sears, A. (2017). Building resilience in social workers: An exploratory study on the impacts of a mindfulness-based intervention. Australian Social Work, 70(1), 17-29. https://doi.org/10.1080/0312407X.2016.1203965

Delgado, L. C., Guerra, P., Perakakis, P., Vera, M. N., del Paso, G. R., \& Vila, J. (2010). Treating chronic worry: Psychological and physiological effects of a training programme based on mindfulness. Behaviour research and therapy, 48(9), 873-882. https://doi.org/10.1016/j.brat.2010.05.012

Delle Fave, A., Brdar, I., Freire, T., Vella-Brodrick, D., \& Wissing, M. P. (2011). The eudaimonic and hedonic components of happiness: Qualitative and quantitative findings. Social indicators research, 100(2), 185-207. https://doi.org/10.1007/s11205$\underline{010-9632-5}$ 
Diener, E. (1984). Subjective well-being. Psychological Bulletin, 95, 542-575. https://doi.org/10.1007/978-90-481-2350-6_2

Diener, E., Suh, E. M., Lucas, R. E., \& Smith, H. L. (1999). Subjective well-being: Three decades of progress. Psychological bulletin, 125(2), 276. https://doi.org/10.1037/0033$\underline{2909.125 .2 .276}$

Diener, E., Wirtz, D., Tov, W., Kim-Prieto, C., Choi, D., Oishi, S., \& Biswas-Diener, R. (2009). New measures of well-being: Flourishing and positive and negative feelings. Social Indicators Research, 39, 247-266. https://www.researchgate.net/publication/304673145 New_measures_of wellbeing Flourishing and positive and negative feelings

Diener, E., Wirtz, D., Tov, W., Kim-Prieto, C., Choi, D., Oishi, S., \& Biswas-Diener, R. (2010). New well-being measures: Short scales to assess flourishing and positive and negative feelings. Social Indicators Research, 97(2), 143-156. https://doi.org/10.1007/s11205-0099493-y

Dodge, R., Daly, A. P., Huyton, J., \& Sanders, L. D. (2012). The challenge of defining wellbeing. International Journal of Wellbeing, 2(3), 222-235. https://doi.org/10.5502/ijw.v2.i3

Dollete, M., Steese, S., Phillips, W., Matthews, G. (2004). Understanding girls' circle as an intervention on perceived social support, body image, self-efficacy, locus of control and self-esteem. The Journal of Psychology, 90(2), 204-215. http://search.ebscohost.com/login.aspx?direct=true \&db=a9h\&AN=20634719\&site=ehost $\underline{\text {-live }}$ 
Ehrich, L., Tennent, L., \& Hansford, B. (2002). A review of mentoring in education: some lessons for nursing. Contemporary Nurse, 12(3), 253-264. https://doi.org/10.5172/conu.12.3.253

Eisenberg, D., Golberstein, E., \& Hunt, J. B. (2009). Mental health and academic success in college. The BE Journal of Economic Analysis \& Policy, 9(1). https://doi.org/10.2202/1935-1682.2191

El-Ghoroury, N. H., Galper, D. I., Sawaqdeh, A., \& Bufka, L. F. (2012). Stress, coping, and barriers to wellness among psychology graduate students. Training and Education in Professional Psychology, 6(2), 122. https://doi.org/10.1037/a0028768

Ellingsen, R., Baker, B. L., Blacher, J., \& Crnic, K. (2014). Resilient parenting of children at developmental risk across middle childhood. Research in developmental disabilities, 35(6), 1364-1374. https://doi.org/10.1016/j.ridd.2014.03.016

Epstein, R. M. (1999). Mindful practice. Jama, 282(9), 833-839. https://doi.org/10.1001/jama.282.9.833

Erikson, E. H. (1963). Childhood and society. New York: NOIrt. On.

Everall, R. D., Altrows, K. J., \& Paulson, B. L. (2006). Creating a future: A study of resilience in suicidal female adolescents. Journal of Counseling \& Development, 84(4), 461-470. https://doi.org/10.1002/j.1556-6678.2006.tb00430.x

Fletcher, D., \& Sarkar, M. (2013). Psychological resilience: A review and critique of definitions, concepts, and theory. European Psychologist, 18(1), 12-23. https://doi.org/10.1027/1016$\underline{9040 / \mathrm{a} 000124}$ 
Foubert, J. D., \& Urbanski, L. A. (2006). Effects of involvement in clubs and organizations on the psychosocial development of first-year and senior college students. NASPA journal, 43(1), 166-182. https://doi.org/10.2202/1949-6605.1576

Frankl, V. E. (1963). Man's search for meaning: An introduction to logotherapy New York, NY: Washington Square Press.

Fried, R., \& Grimaldi, J. (1993). The psychology and physiology of breathing in behavioral medicine, clinical psychology and psychiatry. New York: Plenum.

Gall, T. L., Evans, D. R., \& Bellerose, S. (2000). Transition to first-year university: Patterns of change in adjustment across life domains and time. Journal of Social and Clinical Psychology, 19(4), 544-567. https://doi.org/10.1521/jscp.2000.19.4.544

Garcia-Alandete, J. (2015). Does meaning in life predict psychological well-being. European Journal of Counselling Psychology, 3(2), 89-98. https://doi.org/10.5964/ejcop.v3i2.27

Garmezy, N. (1991). Resilience in children's adaptation to negative life events and stressed environments. Pediatric Annals, 20(9), 459-466. https://doi.org/10.3928/0090-4481$\underline{19910901-05}$

Garmezy, N., Masten, A. S., \& Tellegen, A. (1984). The study of stress and competence in children: A building block for developmental psychopathology. Child Development, 55, 97-111. https://doi.org/10.1111/j.1467-8624.1984.tb00276.x

Germer, K. (2009). The mindful path to self-compassion: Freeing yourself from destructive thoughts and emotions. New York: The Guilford Press.

Gilbert, D., \& Waltz, J. (2010). Mindfulness and health behaviors. Mindfulness, 1(4), 227-234. https://doi.org/10.1007/s12671-010-0032-3 
Gillham, J. E., Jaycox, L. H., Reivich, K. J., Hollon, S. D., Freeman, A., DeRubeis, R. J., \& Seligman, M. E. P. (1991). The APEX Project: Manual for group leaders. Unpublished manuscript, University of Pennsylvania.

Greenhaus, J. H., Collins, K. M., \& Shaw, J. D. (2003). The relation between work-family balance and quality of life. Journal of vocational behavior, 63(3), 510-531. https://doi.org/10.1016/s0001-8791(02)00042-8

Gulliver, A., Griffiths, K. M., \& Christensen, H. (2010). Perceived barriers and facilitators to mental health help-seeking in young people: a systematic review. BMC psychiatry, 10(1), 113. https://doi.org/10.1186/1471-244X-10-113

Guy, J. D. (2000). Holding the holding environment together: Self-psychology and psychotherapist care. Professional Psychology: Research and Practice, 33, 351-35. https://doi.org/10.1037/0735-7028.31.3.351

Haines, M. E., Norris, M. P., \& Kashy, D. A. (1996). The effects of depressed mood on academic performance in college students. Journal of College Student Development, 37, 519-526. https://psycnet.apa.org/record/1997-42750-005

Hanlon, J. M. (1968). Administration and education: Toward a theory of self-actualization. Belmont, CA: Wadsworth.

Happer, K., Brown, E. J., \& Sharma-Patel, K. (2017). Children's resilience and trauma-specific cognitive behavioral therapy: Comparing resilience as an outcome, a trait, and a process. Child abuse \& neglect, 73, 30-41. https://doi.org/10.1016/j.chiabu.2017.09.021

Hartley, M. T. (2011). Examining the relationships between resilience, mental health, and academic persistence in undergraduate college students. Journal of American College Health, 59(7), 596-604. https://doi.org/10.1080/07448481.2010.515632 
Hodgins, H. S., \& Knee, C. R. (2002). The integrating self and conscious experience. Handbook of self-determination research, 87, 100.

Hotchkiss, J. T., \& Lesher, R. (2018). Factors predicting burnout among chaplains: compassion satisfaction, organizational factors, and the mediators of mindful self-care and secondary traumatic stress. Journal of Pastoral Care \& Counseling, 72(2), 86-98. https://doi.org/10.1177/1542305018780655

Howell, A. J. (2009). Flourishing: Achievement-related correlates of students' well-being. The Journal of Positive Psychology, 4(1), 1-13. https://doi.org/10.1080/17439760802043459

Huberty, J., Green, J., Glissmann, C., Larkey, L., Puzia, M., \& Lee, C. (2019). Efficacy of the Mindfulness Meditation Mobile App "Calm" to Reduce Stress Among College Students: Randomized Controlled Trial. JMIR mHealth and uHealth, 7(6), e14273. https://doi.org/10.2196/14273

Hsu, H. C. (2010). Trajectory of life satisfaction and its relationship with subjective economic status and successful aging. Social Indicators Research, 99(3), 455-468. https://doi.org/10.1007/s11205-010-9593-8

Hu, T., Zhang, D., \& Wang, J. (2015). A meta-analysis of the trait resilience and mental health. Personality and Individual Differences, 76, 18-27. https://doi.org/10.1016/j.paid.2014.11.039

Janssen, B. M., Van Regenmortel, T., \& Abma, T. A. (2011). Identifying sources of strength: resilience from the perspective of older people receiving long-term community care. European journal of ageing, 8(3), 145-156. https://doi.org/10.1007/s10433-011$\underline{0190-8}$ 
Johnson, M. L., Taasoobshirazi, G., Kestler, J. L., \& Cordova, J. R. (2014). Models and messengers of resilience: A theoretical model of college students' resilience, regulatory strategy use, and academic achievement. Educational Psychology, 35(7), 869-885. https://doi.org/10.1080/01443410.2014.893560

Kabat-Zinn, J. (2003). Mindfulness-based interventions in context: past, present, and future. Clinical psychology: Science and practice, 10(2), 144-156. https://doi.org/10.1093/clipsy.bpg016

Keyes, C. L. (2010). Flourishing. The Corsini encyclopedia of psychology, 1-1.

Keyes, C. (2002). The mental health continuum: From languishing to flourishing in life. Journal of Health and Behaviour Research, 43(2), 207-222. https://doi.org/10.2307/3090197

Keyes, C. (2009). The nature and importance of positive mental health in America's adolescents. In Gilman, R., Huebner, E., \& Furlong, M. (Eds.). Handbook of positive psychology in schools. New York: Routledge.

Keyes, C. L., Eisenberg, D., Perry, G. S., Dube, S. R., Kroenke, K., \& Dhingra, S. S. (2012). The relationship of level of positive mental health with current mental disorders in predicting suicidal behavior and academic impairment in college students. Journal of American College Health, 60(2), 126-133. https://doi.org/10.1080/07448481.2011.608393

Kimhi, S., \& Eshel, Y. (2015). The missing link in resilience research. Psychological Inquiry, 26(2), 181-186. https://doi.org/10.1080/1047840x.2014.1002378

Kinman, G., Jones, F., \& Kinman, R. (2006). The well-being of the UK academy, 19982004. Quality in higher education, 12(1), 15-27. https://doi.org/10.1080/13538320600685081 
Knoesen, R., \& Naudé, L. (2018). Experiences of flourishing and languishing during the first year at university. Journal of Mental Health, 27(3), 269-278. https://doi.org/10.1080/09638237.2017.1370635

Kotzé, M., \& Kleynhans, R. (2013). Psychological well-being and resilience as predictors of first-year students' academic performance. Journal of psychology in Africa, 23(1), 51-59. https://doi.org/10.1080/14330237.2013.10820593

Leadbeater, B. J., Kuperminc, G. P., Blatt, S. J., \& Hertzog, C. (1999). A multivariate model of gender differences in adolescents' internalizing and externalizing problems. Developmental psychology, 35(5), 1268. https://doi.org/10.1037/0012-

\section{$\underline{1649.35 .5 .1268}$}

Leary, K. A., \& DeRosier, M. E. (2012). Factors promoting positive adaptation and resilience during the transition to college. Psychology, 3(12), 1215. https://doi.org/10.4236/psych.2012.312A180

Leary, M. R., Tate, E. B. Adams, C. E., Allen, A. B., \& Hancock, J. (2007). Self-compassion and reactions to unpleasant self-relevant events: The implications of treating oneself kindly. Journal of Personality and Social Psychology, 92 (5), 887-904. https://doi.org/10.1037/0022-3514.92.5.887

Lee, R. L. T., \& Yuen Loke, A. J. T. (2005). Health-promoting behaviors and psychosocial wellbeing of university students in Hong Kong. Public Health Nursing, 22(3), 209-220. https://doi.org/10.1111/j.0737-1209.2005.220304.x 
Leighton, J. P., Seitz, P., Chu, M. W., \& Gomez, M. C. B. (2016). Operationalizing the role of trust for student wellbeing, learning and achievement. International Journal of Wellbeing, 6(2), 57-79. https://doi.org/10.5502/ijw.v6i2.467

Levecque, K., Anseel, F., De Beuckelaer, A., Van der Heyden, J., \& Gisle, L. (2017). Work organization and mental health problems in PhD students. Research Policy, 46(4), 868879. https://doi.org/10.1016/j.respol.2017.02.008

Liu, W., Li, Z., Ling, Y., \& Cai, T. (2016). Core self-evaluations and coping styles as mediators between social support and well-being. Personality and Individual Differences, 88, 3539. https://doi.org/10.1016/j.paid.2015.08.044

Lönnqvist, J. E., Paunonen, S., Verkasalo, M., Leikas, S., Tuulio-Henriksson, A., \& Lönnqvist, J. (2007). Personality characteristics of research volunteers. European Journal of Personality: Published for the European Association of Personality Psychology, 21(8), 1017-1030. https://doi.org/10.1002/per.655

Longenecker, R., Zink, T., \& Florence, J. (2011). Teaching and learning resilience: Building adaptive capacity for rural practice. A report and subsequent analysis of a workshop conducted at the rural medical educators conference, Savannah, Georgia, May 18, 2010. The Journal of Rural Health, 28(2), 122-127. https://doi.org/10.1111/j.1748$\underline{0361.2011 .00376 . x}$

Lundman, B., Aléx, L., Jonsén, E., Norberg, A., Nygren, B., Fischer, R. S., \& Strandberg, G. (2010). Inner strength — A theoretical analysis of salutogenic concepts. International journal of nursing studies, 47(2), 251-260. https://doi.org/10.1016/j.ijnurstu.2009.05.020 
Maltby, J., Day, L., \& Hall, S. (2015). Refining trait resilience: Identifying engineering, ecological, and adaptive facets from extant measures of resilience. Plos One, 10(7), e0131826. https://doi.org/10.1371/journal.pone.0131826

MacDonald, G. B., \& Validivieso, R. (2000). Measuring deficits and assets: How we track youth development now, and how we should track it. Washington, DC: Academy for Educational Development, Center for Youth Development and Policy Research.

Mahoney, M. J. (1997). Psychotherapists' personal problems and self-care patterns. Professional Psychology: Research and Practice, 28(1), 14-16. https://doi.org/10.1037/07357028.28.1.14

Masten, A. S., \& Coatsworth, J. D. (1998). The development of competence in favorable and unfavorable environments: Lessons from research on successful children. American Psychologist, 53(2), 205-220. https://doi.org/10.1037/0003-066X.53.2.205

Masten, A. S. (2001). Ordinary magic: Resilience processes in development. American Psychologist, 56(3), 227-238. https://doi.org/10.1037/0003-066X.56.3.227

Masten, A. S. (2015). Ordinary Magic: Resilience in development. New York: Guilford Press. Masten, A. S., \& Reed, M. G. J. (2002). Resilience in development. In C. R. Snyder \& S. J. Lopez (Eds.), Handbook of positive psychology (pp. 74-88). New York, NY: Oxford University Press.

Messer, D. J. (2002). Mastery motivation in early childhood: Development, measurement and social process. London: Taylor and Francis.

Mionk, E. M., \& Mahmood, Z. (1999). Student mental health: A pilot study. Counselling Psychology Quarterly, 12(2), 199-210. https://doi.org/10.1080/09515079908254090 
Moorey, Stirling, Greer, Steven, Watson, Maggie, Gorman, Christine, Rowden, Linda, Tunmore, Robert, Robertson, Bernadette, \& Bliss, Judith. (1991). The factor structure and factor stability of the hospital anxiety and depression scale in patients with cancer. British Journal of Psychiatry, 158(2), 255-259. https://doi.org/10.1192/bjp.158.2.255

Moses, J., Bradley, G. L., \& O’Callaghan, F. V. (2016). When college students look after themselves: Self-care practices and well-being. Journal of student affairs research and practice, 53(3), 346-359. https://doi.org/10.1080/19496591.2016.1157488

Mota, C. P., Costa, M., \& Matos, P. M. (2015). Resilience and deviant behavior among institutionalized adolescents: The relationship with significant adults. Child and Adolescent Social Work Journal, 33(4), 313-325. https://doi.org/10.1007/s10560-015$\underline{0429-\mathrm{X}}$

Myers, S. B., Sweeney, A. C., Popick, V., Wesley, K., Bordfeld, A., \& Fingerhut, R. (2012). Self-care practices and perceived stress levels among psychology graduate students. Training and Education in Professional Psychology, 6(1), 55-66. https://doi.org/10.1037/a0026534

Neff, K. D. (2003). Self-compassion: An alternative conceptualization of a healthy attitude toward oneself. Self and Identity, 2(2), 85-101. https://doi.org/10.1080/15298860309032

Neff, K. D. (2011). Self-compassion, self-esteem, and well-being. Social and personality psychology compass, 5(1), 1-12. https://doi.org/10.1111/j.1751-9004.2010.00330.x

Neff, K. D., Kirkpatrick, K. L., \& Rude, S. S. (2007). Self-compassion and adaptive psychological functioning. Journal of Research in Personality, 41(1), 139-154. https://doi.org/10.1016/j.jrp.2006.03.004 
Nelson, C. R. (2016). Exercise versus relaxation: Compared effectiveness for college students' well-being (Doctoral dissertation, Saint Louis University).

Norcross, J. C. (2000). Psychotherapist self-care: Practitioner-tested, research-informed strategies. Professional Psychology: Research and Practice, 31(6), 710-713. https://doi.org/10.1037/0735-7028.31.6.710

Orbach, I., \& Mikulincer, M. (1998). The body investment scale: Construction and validation of a body experience scale. Psychological Assessment, 10(4), 415-245. https://doi.org/10.1037/1040-3590.10.4.415

Oswalt, S. B., Lederer, A. M., Chestnut-Steich, K., Day, C., Halbritter, A., \& Ortiz, D. (2020). Trends in college students' mental health diagnoses and utilization of services, 20092015. Journal of American College Health, 68(1), 41-51. https://doi.org/10.1080/07448481.2018.1515748

Padesky, C. A., \& Mooney, K. A. (2012). Strengths-based cognitive-behavioural therapy: A four-step model to build resilience. Clinical psychology \& psychotherapy, 19(4), 283290. https://doi.org/10.1002/cpp.1795

Pallant, J. (2013). SPSS survival manual. McGraw-Hill Education (UK).

Pangallo, A., Zibarras, L., Lewis, R., \& Flaxman, P. (2015). Resilience through the lens of interactionism: A systematic review. Psychological Assessment, 27(1), 1-20. https://doi.org/10.1037/pas0000024

Panter-brick, C., Leckman, J. F. (2013). Resilience in child development: Interconnected pathways to wellbeing. Journal of Child Psychology and Psychiatry, 54(4), 333-336. https://doi.org/10.1111/jcpp.12057 
Parker, J., Duffy, J., Wood, L., Bond, B., \& Hogan, M. (2005). Academic achievement and emotional intelligence: Predicting the successful transition from high school to university. Journal of the first-year experience \& students in transition, 17(1), 67-78. https://www.researchgate.net/publication/260518204 Academic achievement and emoti onal intelligence Predicting the successful transition from high school to university

Pike, A., Dawley, S., \& Tomaney, J. (2010). Resilience, adaptation and adaptability. Cambridge journal of regions, economy and society, 3(1), 59-70. https://doi.org/10.1093/cjres/rsq001

Pincus, J. (2006, November). Teaching se $;$ f-care. Paper presented at the meeting of the Pennsylvania Psychological Association on the Ethics Educators Conference, Hardsburg, PA.

Pitzer, J., \& Skinner, E. (2017). Predictors of changes in students' motivational resilience over the school year: The roles of teacher support, self-appraisals, and emotional reactivity. International Journal of Behavioral Development, 41(1), 15-29. https://doi.org/10.1177/0165025416642051

Pollard, E. L., \& Lee, P. D. (2003). Child well-being: A systematic review of the literature. Social Indicators Research, 61(1), 59-78. https://doi.org/10.1023/A:1021284215801

Prevatt, F. F. (2003). The contribution of parenting practices in a risk and resiliency model of children's adjustment. British Journal of Developmental Psychology, 21(4), 469-480. https://doi.org/10.1348/026151003322535174

Prince-Embury, S. (2006). Resiliency Scales for Adolescents: Profiles of personal strengths. San Antonio, TX. Harcourt Assessments. 
Prince-Embury, S., Saklofske, D. H., \& Nordstokke, D. W. (2016). The resiliency scale for young Adults. Journal of Psychoeducational Assessment, 35(3), 276-290. https://doi.org/10.1177/0734282916641866

Reeve, K. L., Shumaker, C. J., Yearwood, E. L., Crowell, N. A., \& Riley, J. B. (2013). Perceived stress and social support in undergraduate nursing students' educational experiences. Nurse education today, 33(4), 419-424. https://doi.org/10.1016/j.nedt.2012.11.009

Reker, G. T., Peacock, E. J., \& Wong, P. T. (1987). Meaning and purpose in life and well-being: A life-span perspective. Journal of gerontology, 42(1), 44-49. https://doi.org/10.1093/geronj/42.1.44

Reivich, K. J., Seligman, M. E., \& McBride, S. (2011). Master resilience training in the US Army. American Psychologist, 66(1), 25-34. https://doi.org/10.1037/a0021897

Rogers, C. (1961). On becoming a person. Boston: Houghton Mifflin.

Rosenman, R., Tennekoon, V., \& Hill, L. G. (2011). Measuring bias in self-reported data. International journal of behavioural \& healthcare research, 2(4), 320. https://doi.org/10.1504/IJBHR.2011.043414

Roth, D. L., \& Holmes, D. S. (1987). Influence of aerobic exercise training and relaxation training on physical and psychologic health following stressful life events. Psychosomatic Medicine, 49(4), 355-365. https://doi.org/10.1097/00006842-198707000-00004

Rothbard, N. P. (2001). Enriching or depleting? The dynamics of engagement in work and family roles. Administrative science quarterly, 46(4), 655-684. $\underline{\text { https://doi.org/10.2307/3094827 }}$ 
Rutter, M. (1987). Psychosocial resilience and protective mechanisms. American journal of orthopsychiatry, 57(3), 316-331. https://doi.org/10.1111/j.1939-0025.1987.tb03541.x

Ryan, R. M., \& Deci, E. L. (2001). On happiness and human potentials: A review of research on hedonic and eudaimonic well-being. Annual Review of Psychology, 52(1), 141-166. https://doi.org/10.1146/annurev.psych.52.1.141

Ryff, C. D. (1989a). Happiness is everything, or is it? Explorations on the meaning of psychological wellbeing. Journal of Personality and Social Psychology, 57, 1069-1081. https://doi.org/10.1037//0022-3514.57.6.1069

Ryff, C. D. (1995). Psychological well-being in adult life. Current Directions in Psychological Science, 4(4), 99-104. https://doi.org/10.1111/1467-8721.ep10772395

Saklofske, D. H., Nordstokke, D. W., Prince-Embury, S., Crumpler, T., Nugent, S., Vesely, A., \& Hindes, Y. (2013). Assessing personal resiliency in young adults: The resiliency scale for children and adolescents. In Resilience in children, adolescents, and adults (pp. 189198). Springer, New York, NY.

Schnettler, B., Miranda, H., Sepúlveda, J., Denegri, M., Mora, M., Lobos, G., \& Grunert, K. G. (2013). Psychometric properties of the Satisfaction with Food-Related Life Scale: application in southern Chile. Journal of Nutrition Education and Behavior, 45(5), 443449. https://doi.org/10.1016/j.jneb.2012.08.003

Sebring, P. B., \& Bryk, A. S. (2000). School leadership and the bottom line in Chicago. Phi Delta Kappan, 81(6), 440-443. https://www-jstor-org.ezproxy.lib.ucalgary.ca/ stable/20439690?pq-origsite $=$ summon\&seq $=1 \#$ metadata info tab contents 
Seligman, M. E., Ernst, R. M., Gillham, J., Reivich, K., \& Linkins, M. (2009). Positive education: Positive psychology and classroom interventions. Oxford review of education, 35(3), 293-311. https://doi.org/10.1080/03054980902934563

Shapiro, S. L., Carlson, L. E., Astin, J. A., \& Freedman, B. (2006). Mechanisms of mindfulness. Journal of clinical psychology, 62(3), 373-386. https://doi.org/10.1002/jclp.20237

Short, E., Kinman, G., \& Baker, S. (2010). Evaluating the impact of a peer coaching intervention on well-being amongst psychology undergraduate students. International Coaching Psychology Review, 5(1), 27-35. https://www.researchgate.net/publication/284072338 Evaluating the impact of a peer coaching intervention on well-being amongst psychology undergraduate students

Silliman, K., Rodas-Fortier, K., \& Neyman, M. (2004). Survey of dietary and exercise habits and perceived barriers to following a healthy lifestyle in a college population. Californian journal of health promotion, 2(2), 10-19. https://doi.org/10.32398/cjhp.v2i2.1729

Silverman, M. N., \& Deuster, P. A. (2014). Biological mechanisms underlying the role of physical fitness in health and resilience. Interface focus, 4(5), 20140040. https://doi.org/10.1098/rsfs.2014.0040

Smith, J. C., Amutio, A., Anderson., J. P., \& Aria, L. A. (1996). Relaxation: Mapping an uncharted world. Biofeedback \& Self-Regulation, 21, 63-90. https://doi.org/10.1007/BF02214150

Sogari, G., Velez-Argumedo, C., Gómez, M. I., \& Mora, C. (2018). College students and eating habits: A study using an ecological model for healthy behavior. Nutrients, 10(12), 1823. https://doi.org/10.3390/nu10121823 
Stack-Cutler, H. L., Parrila, R. K., \& Torppa, M. (2014). Using a multidimensional measure of resilience to explain life satisfaction and academic achievement of adults with reading difficulties. Journal of Learning Disabilities, 48(6), 646-657. https://doi.org/10.1177/0022219414522705

Stice, E., Rohde, P., Seeley, J. R., \& Gau, J. M. (2008). Brief cognitive-behavioral depression prevention program for high-risk adolescents outperforms two alternative interventions: a randomized efficacy trial. Journal of consulting and clinical psychology, 76(4), 595. https://doi.org/10.1037/a0012645

Suldo, S., Thalji, A., \& Ferron, J. (2011). Longitudinal academic outcomes predicted by early adolescents' subjective well-being, psychopathology, and mental health status yielded from a dual factor model. The Journal of Positive Psychology, 6(1), 17-30. https://doi.org/10.1080/17439760.2010.536774

Tabachnick, B. G., \& Fiddell, L. S. (2013). Using multivariate statistics (sixth edition). Pearson: New York.

Tomkowicz, J., \& Bushnik, T. (2003). Who Goes to Post-secondary Education and When, Pathways Chosen by 20 Year-olds. Ottawa: Statistics Canada.

Tugade, M. M., \& Fredrickson, B. L. (2004). Resilient individuals use positive emotions to bounce back from negative emotional experiences. Journal of personality and social psychology, 86(2), 320. https://doi.org/10.1037/0022-3514.86.2.320

Valente, V., \& Marotta, A. (2005). The impact of yoga on the professional and personal life of the psychotherapist. Contemporary Family Therapy. 27(1), 65-80. https://doi.org/10.1007/s10591-004-1971-4 
van der Walt, L., Suliman, S., Martin, L., Lammers, K., \& Seedat, S. (2014). Resilience and post-traumatic stress disorder in the acute aftermath of rape: a comparative analysis of adolescents versus adults. Journal of Child \& Adolescent Mental Health, 26(3), 239-249. https://doi.org/10.2989/17280583.2014.923433

Wadlinger, H. A., \& Isaacowitz, D. M. (2011). Fixing our focus: Training attention to regulate emotion. Personality and Social Psychology Review, 15(1), 75-102. https://doi.org/10.1177/1088868310365565

Ward Struthers, C., Perry, R. P., \& Menec, V. H. (2000). An examination of the relationship among academic stress, coping, motivation, and performance in college. Research in Higher Education, 41(5), 581-592. https://doi.org/10.1023/A:1007094931292

Werner, E. E., \& Smith, R. S. (1982). Vulnerable, but invincible: A longitudinal study of resilient children and youth. New York: McGraw-Hill.

Wilks, S. E. (2008). Resilience amid academic stress: The moderating impact of social support among social work students. Advances in social work, 9(2), 106-125. https://doi.org/10.18060/51

Wilson, C. A., Babcock, S. E., \& Saklofske, D. H. (2019). Sinking or swimming in an academic pool: A study of resiliency and student success in first-year undergraduates. Canadian Journal of Higher Education/Revue canadienne d'enseignement supérieur, 49(1), 60-84. https://doi.org/10.7202/1060824ar

Windle, G. (2011). What is resilience? A review and concept analysis. Reviews in Clinical Gerontology, 21(2), 152-169. https://doi.org/10.1017/S0959259810000420 
Zaleski, E. H., Levey-Thors, C., \& Schiaffino, K. M. (1998). Coping mechanisms, stress, social support, and health problems in college students. Applied Developmental Science, 2(3), 127-137. https://doi.org/10.1207/s1532480xads0203 2

Zakeri, H., Jowkar, B., \& Razmjoee, M. (2010). Parenting styles and resilience. Procedia-Social and Behavioral Sciences, 5, 1067-1070. https://doi.org/10.1016/j.sbspro.2010.07.236 


\author{
APPENDIX A \\ Recruitment Letter to Instructors
}

Dear (name of instructor)

My name is Claire McGuinness and I am a Masters student in the School and Applied Child Psychology program at the University of Calgary.

I am completing a research study to examine the affects of self-care and resilience in first-year undergraduate students well-being. We believe that this research has considerable relevance to students here at the University of Calgary. This study has been approved by the Conjoint Faculties Research Ethics Board.

We are hoping that you will be interested in supporting this research by allowing me come to your (COURSE CODE) lecture on (DATE/TIME) in (LOCATION) for less than 5 minutes to explain the research study to your students and ask for their participation.

Any students who are interested in participating would be able to complete the questionnaire online at their own time and convenience.

It would be greatly appreciated if you would please let me know if this opportunity to speak to your students about the research may be a possibility. Please do not hesitate to contact me if you have any questions or wish to discuss further this proposal.

Thank-you in advance for your time and consideration of this research.

I look forward to hearing from you.

Sincerely,

Claire McGuinness 


\section{APPENDIX B}

\section{Classroom Recruitment Script}

\section{Hello Everyone,}

My name is Claire McGuinness and I am a MSc Student in the School and Applied Child Psychology program. I am involved in an exciting research project here at the University of Calgary that I am inviting you to participate in. This study has been approved by the Conjoint Faculties Research Ethics Board.

This research involves the study of self-care and resilience in first-year undergraduate students. We wish to explore whether this factor predicts psychological well-being. The emergent stressors of first-year can be quite daunting for students, but literature has shown benefits of selfcare and resilience in mitigating distress.

If you agree to participate in this research project, you will complete an online survey that asks questions about your background history, self-care practices, resilience, psychological wellbeing, academic stress, grade point average, anxiety and depression. The online survey will take approximately 20 - 25 minutes to complete and your participation is completely voluntary. Should you choose to participate and complete the study, you will have the option to provide an email address to be entered into a draw to win one of three \$25 Amazon gift-cards.

We would be most grateful if you would agree to participate in this research project. If you are interested or would like more information, please send an email to claire.mcguinness1@ucalgary.ca. However, your decision to participate in the research study or not will have no effect on your grade or standing in the course.

Thank you very much for your time, and I hope you enjoy the remaining portion of your semester. 


\section{APPENDIX C}

Informed Consent Form

\section{CALGARY}

\section{Name of Researcher, Faculty, Department, \& Email:}

Claire McGuinness | Werklund School of Education | School \& Applied Child Psychology | claire.mcguinness1@ucalgary.ca

\section{Supervisor:}

Dr. David W. Nordstokke | Assistant Professor | Werklund School of Education

\section{Title of Project:}

Self-care and resilience in first-year undergraduate students

This consent form, is only part of the process of informed consent. If you want more details about something mentioned here, or information not included here, you should feel free to ask. Please take the time to read this carefully and to understand any accompanying information.

The University of Calgary Conjoint Faculties Research Ethics Board has approved this research study.

\section{Purpose of the Study}

The purpose of this study is to examine the importance of self-care and resilience during the transition from high school into post-secondary studies in terms of how it helps students adapt to this novel environment. The results of this study will provide clarity regarding the utility of selfcare and resilience during this time and outline specific areas that could be used in future prevention and intervention initiatives.

\section{What Will I Be Asked To Do?}

You will complete an online survey that asks questions about your background (e.g., age, gender, living arrangements, and grade point average), self-care practices, resilience, psychological wellbeing, academic stress, grade point average, anxiety and depression, and supply a valid email address. The online survey will take approximately 20-25 minutes to complete and your 
participation is completely voluntary. As this study is voluntary, you are free to discontinue participation at any time without consequence.

Should you choose to participate and complete the study, you can be entered into a draw to win one of three \$25 Amazon gift-cards. Following the completion of the online survey, you can choose to provide a valid email address in order to be entered into the draw and be contacted by the Study Coordinator for prize disbursement.

\section{$\underline{\text { What Type of Personal Information Will Be Collected? }}$}

Should you agree to participate, you will be asked to provide your age, gender,living arrangement, and GPA. Additionally, if you wish to be entered into the draw to win 1 of $3 \$ 25$ Amazon gift cards, an email address will be required. Your email address will be stored separately from the survey.

\section{Are there Risks or Benefits if I Participate?}

Participation in this study will provide you with insight into self-care practices. Additionally the results have the potential to secondary and post-secondary institutions to identify and provide remediation for students who are at a heightened risk for poor performance and drop-out in higher learning. In doing so, this study will provide parents and educators with identified domains and strategies that can used as the basis of prevention and intervention initiatives, and ultimately help students manage for the numerous challenges and psychological stressors that will likely appear upon entering post-secondary education. There is a risk that you may feel discomfort while discussing self-care practices, stress, anxiety or depression. The contact information of the University of Calgary Health and Wellness Centre and the Distress Centre will be provided.

\section{What Happens to the Information I Provide?}

Only the investigator and the supervisor will have access to the data collected for this study. The data will be downloaded and stored on a password protected and encrypted research laptop for future use. The raw data will be put into a database and be summarized for use in research projects that may be published or presented at conferences. You are free to discontinue participation at any time during the study. If you choose to discontinue participation during the study, all data collected up to the point of discontinuation may be retained indefinitely for possible future use.

Questions/Concerns

If you have any further questions or want clarification regarding this research and/or your participation, please contact:

Claire McGuinness

School and Applied Child Psychology - Werklund School of Education

Email: claire.mcguinness1@ucalgary.ca 
Dr. David W. Nordstokke

School and Applied Child Psychology - Werklund School of Education

Email: dnordsto@ucalgary.ca

If you have any concerns about the way you've been treated as a participant, please contact the Research Ethics Analyst, Research Services Office, University of Calgary at (403) 220-6289 or (403) 220-8640; email cfreb@ucalgary.ca.

If you would like to request a copy of this consent form, please contact Claire McGuinness or Dr. David W. Nordstokke.

\section{Signatures}

By clicking "Yes" on the toggle response options found below, you indicate that 1) you understand to your satisfaction the information provided to you about your participation in this research project, 2) you agree to participate in this research project, and 3) you agree to be contacted via the supplied email if you win the draw.

In no way does this waive your legal rights nor release the investigators, sponsors, or involved institutions from their legal and professional responsibilities. You are free to discontinue participation from this research project at any time. You should feel free to ask for clarification or new information throughout your participation

O Yes

$\mathrm{O}$ No 


\section{APPENDIX D}

\section{Certification of Conjoint Faculties Research Ethics Board (CFREB) Approval}

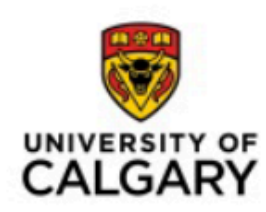

Conjoint Faculties Research Ethics Board

Research Services Office 2500 University Drive, NW

Calgary AB T2N $1 \mathrm{~N} 4$

Telephone: (403) 220-4283/6289

cfreb@ucalgary.ca

\section{CERTIFICATION OF INSTITUTIONAL ETHICS REVIEW}

The Conjoint Faculties Research Ethics Board (CFREB), University of Calgary has reviewed and approved the below research. The CFREB is constituted and operates in accordance with the current version of the Tri-Council Policy Statement: Ethical Conduct for Research Involving Humans (TCPS).

Ethics ID:

Principal Investigator:

Co-Investigator(s):

Student Co-Investigator(s):

Study Title:

Sponsor:

Effective: 28-Aug-2019
REB19-0854

David Nordstokke

There are no items to display

Claire McGuinness

Examining resilience as a mediator of self-care and psychological wellbeing in first-year undergraduate students

\section{Restrictions:}

\section{This Certification is subject to the following conditions:}

1. Approval is granted only for the research and purposes described in the application.

2. Any modification to the approved research must be submitted to the CFREB for approval.

3. An annual application for renewal of ethics certification must be submitted and approved by the above expiry date.

4. A closure request must be sent to the CFREB when the research is complete or terminated.

Approved By:

Jenny Godley, $\mathrm{PhD}$, Chair, CFREB
Date:

28-Aug-2019

Note: This correspondence includes an electronic signature (validation and approval via an online system). 